\title{
DIAGNÓSTICO DEL EMPLEO EN GIPUZKOA ${ }^{1}$
}

\author{
Verónica Castrillón Serna \\ Jose Mari ZendoIA SAINZ \\ Jon BERNAT Zubiri ReY \\ Departamento de Economía Aplicada I \\ Euskal Herriko Unibertsitatea / Universidad del País Vasco (UPV/EHU)
}

DOI: $10.1387 /$ lan-harremanak.16562

\section{ABSTRACT}

En el presente articulo hacemos un repaso a diferentes variables relacionadas con la ocupación laboral y el empleo asalariado en Gipuzkoa, observando su evolución a lo largo de los últimos años, con especial atención en los años posteriores a la crisis global iniciada en 2007, que como efecto más evidente han producido un aumento del paro y de la precariedad. A lo largo de los diferentes apartados se va exponiendo la evolución de la población, la actividad, la ocupación laboral y diferentes aspectos relacionados con las condiciones del empleo asalariado, atendiendo escuetamente a las múltiples tendencias que pueden obtenerse de un análisis de los principales datos disponibles. Se finaliza esta primera etapa de nuestro diagnóstico con un estudio más exhaustivo a nivel sectorial sobre la jornada laboral, que no hace sino indicar las líneas de profundización que siguen en Castrillón et al. (2016b; 2016c y 2016d).

Palabras clave: empleo, tipos de contrato, tasa de actividad, jornada laboral, Gipuzkoa.

${ }^{1}$ La autoría de este artículo está indicada por orden alfabético, justificada en el trabajo equitativamente compartido de análisis del reparto del tiempo de trabajo, en el marco del Proyecto de Investigación «Reparto del empleo y del tiempo de trabajo: efectos en la fiscalidad y tratamiento jurídico», financiado por el Departamento de Innovación de la Diputación Foral de Gipuzkoa, a ejecutar entre el 22-12-2014 y el 30-10-2015. 
In this article we review a series of variables in connection with labour relations and paid employment in Gipuzkoa, and their evolution in the recent past, with special attention to the years after the global crisis that began in 2007. Some of the most obvious effects of this crisis have been an increase in unemployment and job insecurity. Throughout the different sections we examine the evolution of the population, activities, occupation and other issues related to the conditions of paid employment, briefly addressing the multiple trends that can be derived from an analysis of the main data available. This first stage of our diagnosis is completed with further study on working time in different sectors of activity, which points to the arguments developed in depth in Castrillón et al. (2016b; 2016c and 2016d).

Keywords: employment, types of contract, rate of activity, working time, Gipuzkoa.

Artikulu honetan Gipuzkoako laneko okupazioarekin eta soldapeko enpleguarekin erlazionaturiko aldagai desberdinen berrikusketa egiten dugu, horretarako haien azken urteetako garapena aztertuz eta, batez ere, langabezia eta prekarietatea sortu dituen 2007 urtean hasitako krisi globala kontuan harturik. Atal desberdinetan zehar, biztanleriaren garapena, jarduera, laneko okupazioa eta soldatapeko enpleguren alderdi desberdinak azaltzen dira, dauzkagun datu garrantzitsuenetik erator daitezkeen tendentziak kontuan harturik. Gure diagnostikoaren lehen etapa maila sektorialeko jardunaldiaren azterketa zehatzarekin amaitzen da, zeinek Castrillónen eta beste batzuen sakontze-lerroak besterik ez duen adierazten.

Hitz gakoak: enplegua, kontratu motak, jarduera-tasa, lanaldia, Gipuzkoa. 


\section{Introducción}

En este artículo se realiza un análisis exhaustivo de la situación actual de la ocupación laboral y el empleo asalariado en Gipuzkoa, así como su evolución en los últimos años, en el contexto del marco vasco, español ${ }^{2}$ y del europeo. Además de describir las principales variables relacionadas con el trabajo (tasas de actividad y de paro, edad, género, tipos de contratos), hemos realizado un análisis pormenorizado de la evolución de la jornada laboral en los sectores económicos que más empleo generan en el territorio. Este diagnóstico se continua en Castrillón et al. (2016b; 2016c), mediante un estudio general y sectorial más detallado de las variables centrales en el empleo, la distribución de la renta, los costes laborales unitarios y la evolución de la jornada de trabajo. En la línea de lo apuntado por De la Fuente y Zubiri (2016a), nuestro objetivo es ir abriendo el camino a la implantación de políticas de reducción del tiempo de trabajo, para lo cuál hemos realizado, también en otro artículo, unas primeras proyecciones para Gipuzkoa (Castrillón et al., 2016d).

Tras la presentación, en el segundo apartado se detalla la evolución del empleo en los diferentes sectores económicos (agropecuario, industria y construcción, servicios) para ver cómo el sector servicios acapara la gran parte del empleo, si bien en Gipuzkoa la industria tiene más peso que en las economías circundantes. También se analiza la evolución del desempleo en las últimas décadas, observando la relación directa entre épocas de crisis y aumento del paro.

A continuación estudiamos, en el tercer apartado, la actividad y el paro desde una perspectiva de edad: por una parte constatamos que los trabajadores activos tienen una edad media cada vez mayor y que el índice de reemplazo se reduce, y por otra parte observamos cómo la tasa de paro es mucho más elevada entre los jóvenes, especialmente en los años en que el desempleo total es mayor. En el cuarto apartado completamos este análisis con una constatación de la ba-

2 No habiendo estudios exhaustivos que diagnostiquen la estructura del empleo y las relaciones laborales para la CAPV y Euskal Herria, algunos datos pueden verse en Gaindegia (2014) y ELA (2014). En Aragón et al. (2012), así como anteriormente en Miguelez y Prieto (1999), se realiza un estudio más exhaustivo de la ocupación y el empleo en España. Una perspectiva europea en el actual contexto de crisis y ajuste contra la mayoría trabajadora puede abordarse en Álvarez et al. (2013). 
jada del índice de remplazo entre jóvenes y seniors, con el consiguiente envejecimiento general de la población activa.

En cuanto a otras variables, en el quinto apartado hacemos una referencia a la proporción de trabajadores por cuenta propia, asalariados y cooperativistas, la evolución de estas proporciones a lo largo del tiempo y la diferencia entre el mercado laboral de Gipuzkoa y España, constatando aquí una diferencia sustancial en la proporción de trabajadores cooperativistas, casi insignificante en el caso espańol y más importante en el gipuzkoano.

También nos detenemos a estudiar, en el sexto apartado, la distribución de la población trabajadora según el tipo de contrato, que nos señala, tal y como era previsible debido a las consecuencias de la crisis y los desarrollos de la legislación laboral, la disminución del número de trabajadores con contrato indefinido (en número absoluto y en proporción), y el aumento de los trabajadores con contratos temporales.

En cuanto a las diferencias entre hombres y mujeres, analizamos con detalle diferentes variables para la CAV o para Gipuzkoa, tales como la tasa de actividad y de paro, la ganancia salarial o los tipos de jornada y contrato, que vienen a mostrar el mayor grado de precariedad y discriminación que sufren las mujeres trabajadoras con respecto a los hombres.

En el octavo apartado de este artículo nos preguntamos si la tasa de actividad sería diferente en Gipuzkoa en el caso en que el desempleo fuera mucho menor, dado que podemos suponer que en el caso de que se aplicasen medidas de reducción de tiempo de trabajo que disminuyeran la tasa de paro, probablemente un número de trabajadores actualmente desanimados entrarían de nuevo en las relaciones laborales o asalariadas, con lo que sería mayor el número de personas entre las que repartir el trabajo. Sin embargo, y si comparamos el caso vasco con regiones comparables de la UE, no nos atrevemos a afirmar que este aumento de la tasa de actividad sería muy grande.

Finalmente, en el noveno apartado, se ha analizado pormenorizadamente la evolución de las jornadas laborales medias por sectores, teniendo en cuenta al conjunto de la población trabajadora, y también para el caso más específico de los asalariados (puesto que consideramos que las políticas de RTT son más factibles de aplicar en este colectivo).

\section{Evolución de la ocupación en las últimas décadas}

En los siguientes gráficos (figuras 1 a 6) se recoge la evolución de distintas variables para tres ámbitos territoriales de comparación para el periodo com- 
prendido entre los años 1985 y 2014, en el caso de Gipuzkoa y de Espańa, y para el periodo 1995-2013 para el caso de la Eurozona18 (por falta de datos).

En el primero de los gráficos de cada ámbito aparece la evolución del número de activos, y de entre ellos, el número de personas ocupadas y el de parados. También se incluye la tasa de paro (parados/activos). En el segundo de los gráficos se muestra la evolución del número de personas ocupadas en los cuatro grandes sectores económicos (agropecuario, industria, construcción y servicios).

Se pretende con estos gráficos ver las principales tendencias acaecidas en la ocupación, intentando ver cuáles son las semejanzas entre los diferentes ámbitos territoriales, y cuáles las especificidades de cada uno.

\subsection{Evolución de activos, parados y ocupados por sectores}

\section{Gipuzkoa}

Figura 1

Número de activos, parados y ocupados. Tasa de paro.

Gipuzkoa (1985-2014)

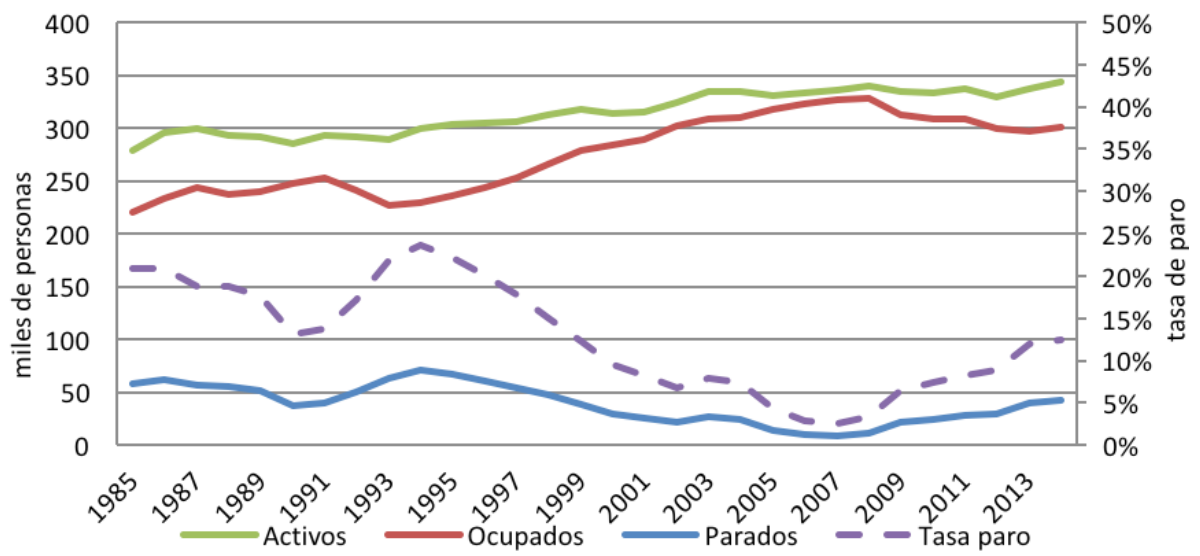

Fuente: Eustat. 
Figura 2

Ocupados por sectores.

Gipuzkoa (1985-2014)

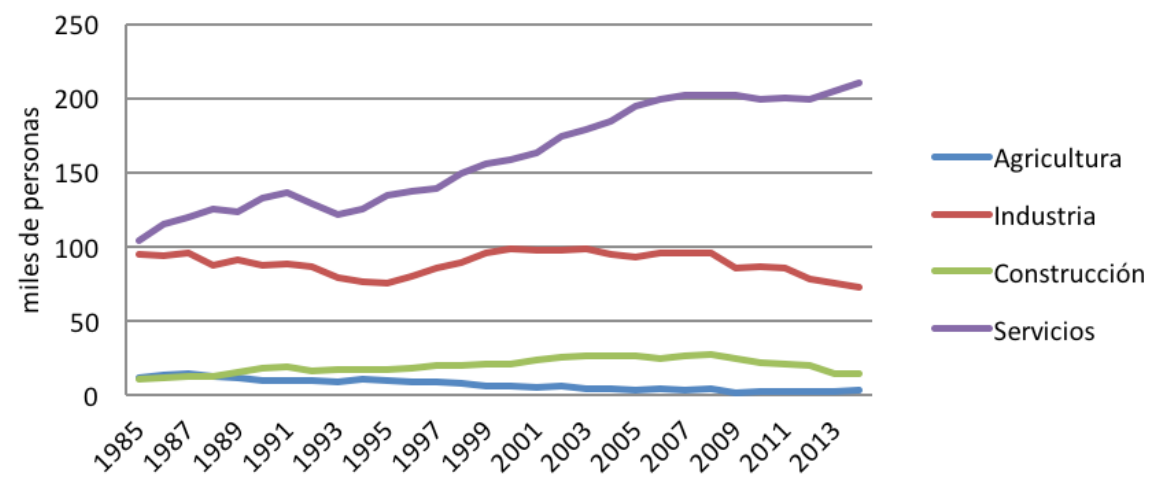

Fuente: Eustat.

\section{España}

Figura 3

Número de activos, parados y ocupados. Tasa de paro.

Espańa (1985-2014)

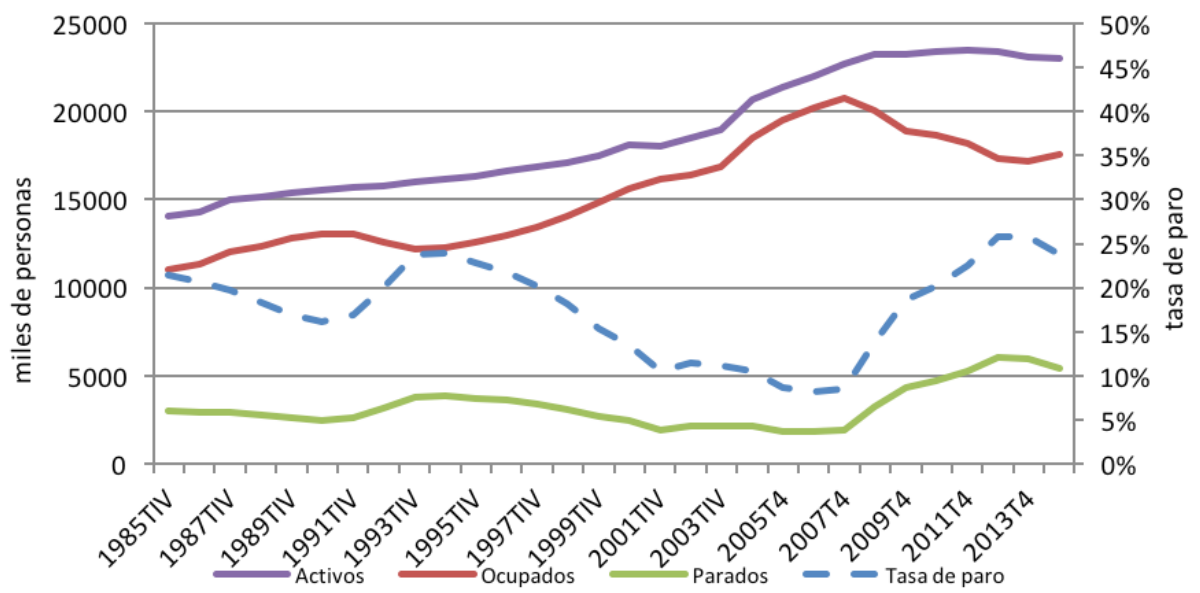

Fuente: INE. 
Figura 4

Ocupados por sectores. España (1985-2014)

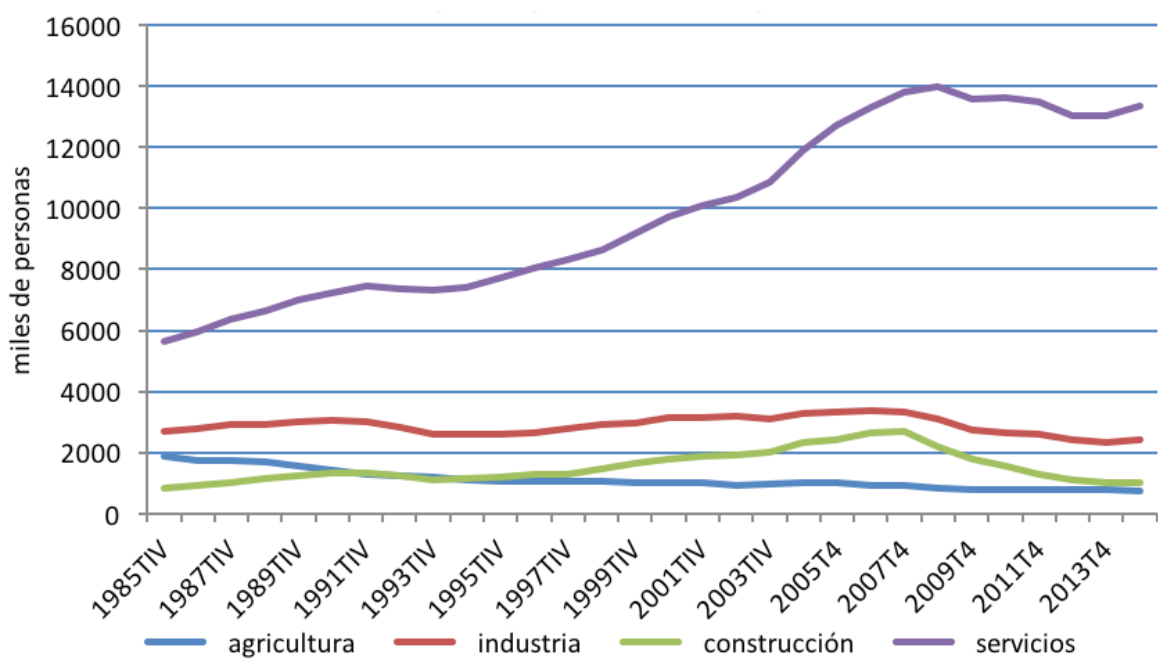

Fuente: INE.

\section{Eurozona ${ }^{3}$}

Figura 5

Número de activos, parados y ocupados. Tasa de paro. Eurozona (1995-2013)

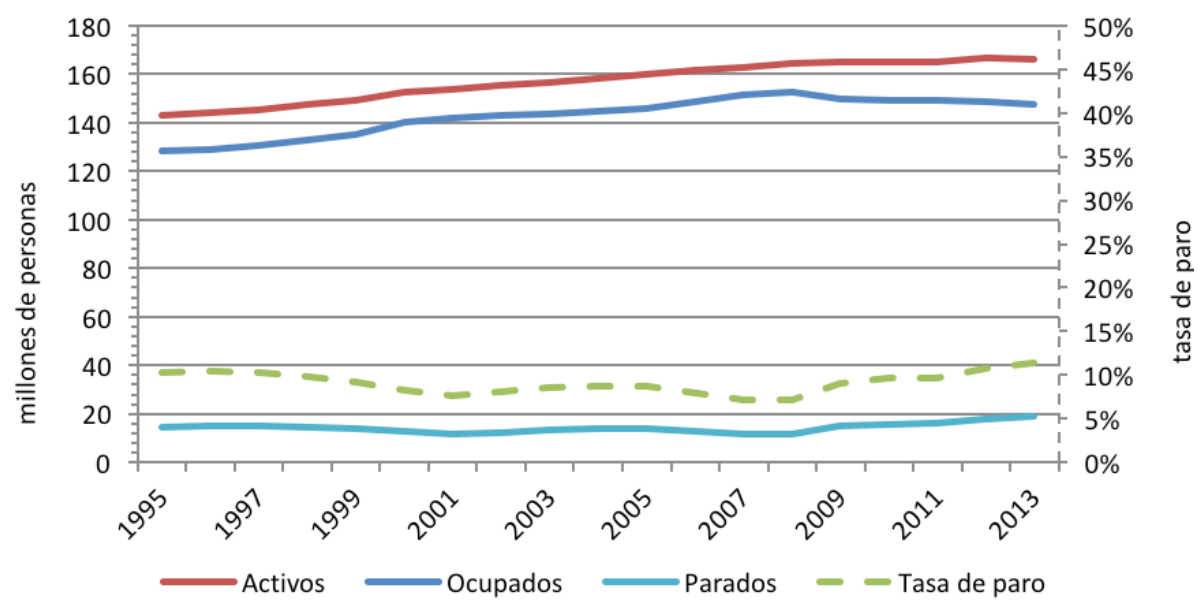

Fuente: Eurostat. zona18.

3 Para el periodo 1995-1999, suma de Eurozona17+Latvia, a partir de 2000, datos de Euro- 
Figura 6

Ocupados por sectores.

Eurozona (1995-2013)

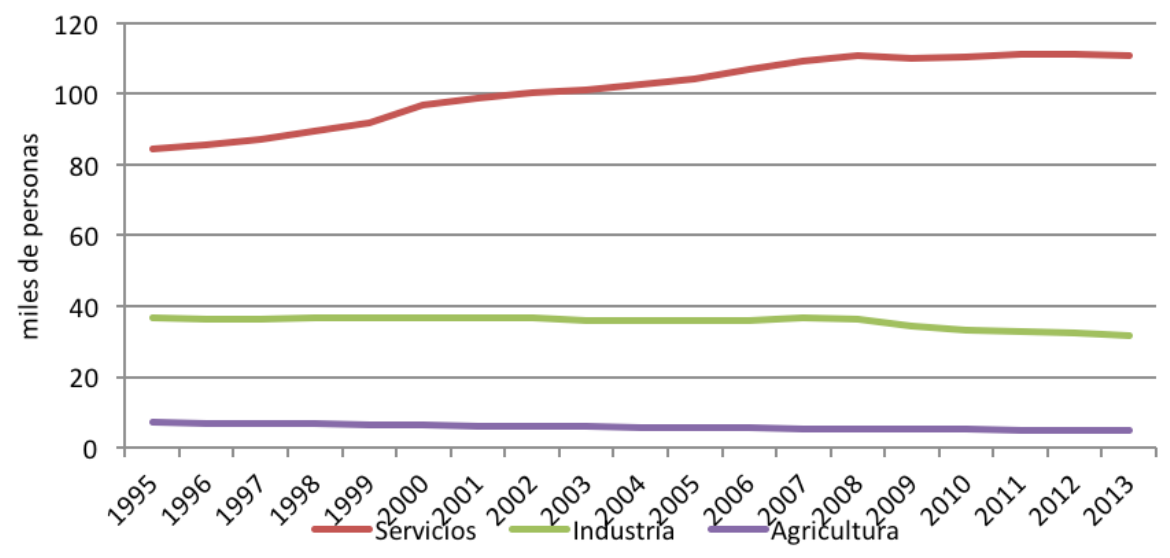

Fuente: Eurostat.

Como puntos principales, cabe señalar:

- El incremento paulatino del número de activos, con un repunte significativo en el caso de España entre los años 2004 y 2008 (inmigración masiva).

- Los altibajos de la tasa de paro, mayores para el caso de Espańa y de Gipuzkoa que para el caso europeo, con unos valores máximos hacia 1995, una paulatina disminución hasta los mínimos de 2007 (5\% en Gipuzkoa, $10 \%$ en España y $8,5 \%$ en la eurozona), y un repunte desde el comienzo de la crisis hasta los valores actuales.

- El aumento del número de ocupados en el sector servicios, duplicándose en el caso de Gipuzkoa, y aún más que duplicándose en España.

- Un cierto declive en el número de ocupados en la industria, con el dato relevante de que en Gipuzkoa son casi la cuarta parte de los ocupados en el último año considerado, para un 14\% en España, y un $21 \%$ en la Eurozona (pero en este último caso incluyendo la construcción).

- Un aumento de los ocupados en la construcción hasta el estallido de la burbuja inmobiliaria, y un retroceso posterior.

- Un lento declive en la agricultura, sector que ya era el que contaba con menos ocupados, con un cierto repunte en Gipuzkoa a partir del estallido de la crisis. 


\subsection{Análisis del periodo $2005-2014$}

Más en concreto, en las siguientes tablas recogemos la información de las variables señaladas en los años 1985, 2005 y 2014, y a continuación hacemos un breve comentario de lo que ha supuesto en líneas generales la actual crisis económica en lo que se refiere a los grandes números laborales.

\section{Gipuzkoa}

En los últimos 10 años (2005-2014), en Gipuzkoa, según el Eustat:

Ha descendido el número de ocupados en Agricultura (-300, el 8,3\% de los que existían), Industria ( -19.900 , el $21,5 \%$ de los que había) y Construcción $(-12.400$, un $46,62 \%)$, mientras que ha aumentado en Servicios (16.100, un crecimiento del $8,29 \%)$

Tabla 1

Ocupados por sectores (miles). Total ocupados, parados, activos.

Diferencia entre 2005 y 2014. Gipuzkoa

\begin{tabular}{lrrrrr}
\hline & 1985 & 2005 & 2014 & Dif 05-14 miles & Dif 05-14\% \\
\hline Agricultura-ganad-pesca & 11,1 & 3,6 & 3,3 & $-0,3$ & $-8,33 \%$ \\
Industria & 94,9 & 92,5 & 72,6 & $-19,9$ & $-21,51 \%$ \\
Construcción & 10,9 & 26,6 & 14,2 & $-12,4$ & $-46,62 \%$ \\
Servicios & 103,9 & 194,3 & 210,4 & 16,1 & $8,29 \%$ \\
\hline Total ocupados & 220,8 & 317 & 300,5 & $-16,5$ & $-5,21 \%$ \\
\hline Total parados & 58,4 & 14,1 & 42,9 & 28,8 & $204,26 \%$ \\
\hline Total activos & 279,2 & 331,1 & 343,4 & 12,3 & $3,71 \%$ \\
\hline Tasa paro & $20,92 \%$ & $4,26 \%$ & $12,49 \%$ & & \\
\hline
\end{tabular}

Fuente: Eustat.

En el conjunto de los cuatro sectores hay 16.500 ocupados menos, un $5,21 \%$ de los 317.000 existentes en 2005 .

Teniendo en cuenta que en ese periodo ha aumentado la población activa en 12.300 personas (un 3,71\% más), resulta que en 2014 hay 28.800 parados más que en 2005: un aumento del 204\%, o lo que es lo mismo, el número de desempleados se ha triplicado en el periodo, al pasar de 14.100 a 42.900 personas (con lo que la tasa de paro ha pasado del 4,26\% al 12,49\%). 


\section{España}

Para España, según datos del INE, ha descendido el número de ocupados en Agricultura (29\% menos), Industria (26,5\% menos) y Construcción $(57,53 \%)$, mientras que ha aumentado en Servicios (4,97\% más). Esto supone un $9,94 \%$ menos de personas ocupadas en el estado, para el periodo considerado.

Tabla 2

Ocupados por sectores (miles). Total ocupados, parados, activos.

Diferencia entre 2005 y 2014. Espańa

\begin{tabular}{lrrrrr}
\hline & \multicolumn{1}{c}{1985} & \multicolumn{1}{c}{2005} & \multicolumn{1}{c}{2014} & Dif 05-14 miles & Dif 05-14\% \\
\hline Agricultura-ganad-pesca & 1884,3 & $1.027,5$ & 728,9 & $-298,6$ & $-29,06 \%$ \\
Industria & $2.691,3$ & $3.317,3$ & $2.438,8$ & $-878,5$ & $-26,48 \%$ \\
Construcción & 839,8 & $2.426,3$ & $1.030,4$ & $-1.395,9$ & $-57,53 \%$ \\
Servicios & $5.618,9$ & $12.738,2$ & $13.371,0$ & 632,8 & $4,97 \%$ \\
\hline Total ocupados & $11.056,3$ & $19.509,2$ & $17.569,1$ & $-1.940,1$ & $-9,94 \%$ \\
\hline Total parados & 3024,4 & $1.860,3$ & $5.457,7$ & $3.597,4$ & $193,38 \%$ \\
\hline Total activos & $14.080,7$ & 21369,5 & 23026,8 & $1.657,3$ & $7,76 \%$ \\
\hline Tasa paro & $21,48 \%$ & $8,71 \%$ & $23,70 \%$ & & \\
\hline
\end{tabular}

Fuente: INE.

La tasa de paro ha aumentado considerablemente en este periodo, del 8,71\% a finales de 2005 hasta el 23,7\% a finales de 2014 .

\section{Eurozona18}

Si observamos lo ocurrido en la eurozona18 (en este caso para el periodo 2005-2013, con datos de Eurostat), ha descendido el número de ocupados en Agricultura (12\% menos), e Industria y Construcción (12,23\% menos en conjunto), mientras que ha aumentado en Servicios (6,27\% más). Esto supone un $0,9 \%$ más de personas ocupadas en la eurozona, entre los ańos 2005 y 2013.

La tasa de paro ha aumentado en la eurozona en el periodo considerado, pasando del 8,74\% del año 2005 al 11,44\% del año 2013. 
Tabla 3

Ocupados por sectores (miles). Total ocupados, parados, activos.

Diferencia entre 2005 y 2013 . Eurozona

\begin{tabular}{lrrrrr}
\hline & 1995 & 2005 & \multicolumn{1}{c}{2013} & Dif 05-13 & Dif 05-13\% \\
\hline Agricultura-ganad-pesca & 7.192 & 5.694 & 5.009 & -686 & $-12,04 \%$ \\
Industria+Construcción & 36.732 & 35.918 & 31.525 & -4.392 & $-12,23 \%$ \\
Servicios & 84.380 & 104.249 & 110.781 & 6.532 & $6,27 \%$ \\
\hline Total ocupados & 128.433 & 146.007 & 147.315 & $1.308^{4}$ & $0,90 \%$ \\
\hline Total parados & 14.715 & 13.837 & 19.039 & 5.202 & $37,59 \%$ \\
\hline Total activos & 143.148 & 158.330 & 166.354 & 8.023 & $5,07 \%$ \\
\hline Tasa paro & $10,28 \%$ & $8,74 \%$ & $11,44 \%$ & & \\
\hline
\end{tabular}

Fuente: Eurostat.

\subsection{Dinámica estructural}

Desde la revolución industrial, la agricultura, que hasta el siglo XIX era el sector que ocupaba a un mayor número de personas, fue mecanizando sus procesos de producción, aumentando así la productividad y, como consecuencia, perdiendo mano de obra. La población antes empleada en el sector primario y que había perdido su puesto de trabajo fue encontrando empleo en la industria (y los servicios). Durante buena parte del siglo xx fue la industria el sector que más población empleaba ${ }^{5}$, pero también fue adaptando sus sistemas de producción, renovando las técnicas y mecanizando sus procesos. Todo ello supuso que a cada reconversión industrial fuese quedando sin empleo un número mayor de trabajadores, que habitualmente eran absorbidos por el sector servicios. De hecho, según señala Zamagni (2001), "otra novedad de esta tercera revolución, tal vez todavía más impropiamente que las otras llamada "industrial», es el gran aumento de la ocupación en los servicios, tanto que muchos hablan de una era postindustrial».

En las últimas décadas la agricultura y la industria han seguido perdiendo empleo, que en su mayor parte iba a parar a los servicios (Aznar, 1994; Albarra-

${ }^{4} \mathrm{El}$ aumento de ocupados para el periodo $05-13$ no coincide si se toma el dato total de ocupados, o la suma de ocupados por sectores. Esto es así porque Eurostat no ofrece el número de personas ocupadas en cada sector sino los porcentajes, y a partir de ellos se ha obtenido el número absoluto. Por tanto es más fiable el número absoluto de ocupados que la suma de ocupados por sectores. En cualquier caso los datos sirven para ver las tendencias de cada serie, que es lo que ahora nos interesa.

5 Por ejemplo, en Gipuzkoa, todavía en el año 1985, la industria y la construcción ocupaban al $47,92 \%$ de los empleados, mientras que los servicios ocupaban al 47,06\%. 
cín, 2003), siendo en sus diversas modalidades y de forma más concentrada la puerta de entrada de las nuevas generaciones al empleo remunerado (Zubiri, 2014). Desde el estallido de la crisis actual, sin embargo, este proceso se ha detenido, al menos en la cuantía en la que venía ocurriendo anteriormente, con lo que el número de parados ha aumentado considerablemente.

Este proceso se ha dado con diferentes características en los ámbitos considerados (Gipuzkoa, Comunidad Autónoma Vasca-CAV, España, Eurozona-18), debido a las condiciones iniciales de la estructura económica de cada uno de ellos. Sin embargo, y teniendo en cuenta dichas matizaciones, el resultado final viene a mostrar que la agricultura es un sector residual (en cuanto al número de personas empleadas), la industria ha seguido un declive progresivo y ya no es capaz de generar nuevo empleo, sino que sigue perdiendo puestos de trabajo, y es el sector servicios el más amplio en cuanto a la generación de empleo.

Efectivamente, esa división por sectores en el año 2013 era la siguiente, donde se observa que para el caso de Gipuzkoa la agricultura da trabajo a menos del $1 \%$ de la población ocupada (en comparación con el 4,54\% en España o con el 3,4\% de la Eurozona-18), mientras que la industria es un sector con una presencia considerablemente que en los entornos citados, y a su vez, los servicios casi ocupan al 70\% de la población, menos que en el estado o que en la eurozona.

Tabla 4

Porcentaje de personas empleadas por sector

(Gipuzkoa, España, Eurozona). 2013

\begin{tabular}{lrrc}
\hline & Gipuzkoa & España & Eurozona \\
\hline Agricultura & $0,81 \%$ & $4,54 \%$ & $3,40 \%$ \\
Industria & $25,36 \%$ & $13,66 \%$ & $21,40 \%$ \\
Construcción & $4,92 \%$ & $5,78 \%$ & \\
Servicios & $68,90 \%$ & $76,02 \%$ & $75,20 \%$ \\
\hline
\end{tabular}

Fuente: Eustat, INE, Eurostat.

En cualquier caso, al ser el sector terciario tan extenso, acoge a diferentes subsectores de características dispares. En cuanto a los procesos de automatización que estamos señalando, hay subsectores dentro de los servicios, como la banca, susceptibles de vastos programas de informatización que pueden hacer sustituir mucha mano de obra por máquinas y software adecuado, mientras que otros subsectores, como la atención a personas ancianas o discapacitadas, no tienen tanto margen de maniobra en ese aspecto y por tanto no son tan proclives a sustituir empleo por procesos automatizados. 
Por ello, conviene desagregar este sector tan extenso para ver cuáles son los subsectores que pueden generar nuevos puestos de trabajo y cuáles no, labor que desarrollaremos al estudiar las jornadas laborales y los costes laborales unitarios por sectores.

\section{Evolución de las tasas de actividad y paro por grupos de edad}

A continuación vamos a ver una serie de indicadores que reflejan las diferentes situaciones en relación con la actividad y el paro, según tres grupos diferentes de edad: trabajadores de entre 16 y 24 años, trabajadores entre 25 y 44 años y trabajadores de 45 años o más. En primer lugar analizaremos la evolución de la tasa de actividad para dichos grupos de edad entre 1985 y 2014, y a continuación haremos lo mismo con la tasa de paro.

\subsection{Tasa de actividad}

Para la tasa de actividad total, hay que tener en cuenta que el Eustat toma como referencia la población de 16 o más y no la población en edad de trabajar (15-64 años). Es decir, la tasa de actividad indica el porcentaje de personas trabajando o buscando empleo, dentro de la población de referencia ${ }^{6}$. Para el caso de Gipuzkoa se observa que la tasa de actividad se ha mantenido en un rango entre el 50 y el 60\%, con una ligera disminución en los primeros años del periodo (1985-1993), y un posterior incremento en los siguientes años.

En el grupo de los trabajadores más jóvenes (16-24 años), la tasa de actividad descendió desde valores cercanos al 55\% a finales de los 80 hasta valores cercanos al 40\% en los que se estabilizó durante los 90 y hasta 2003. A partir de entonces volvió a reduciros, con valores mínimos del 30\% entre los años 2010 y 2012, con un repunte en los últimos dos años considerados (2013 y 2014).

En el grupo de trabajadores entre 25 y 44 años se dan las tasas de actividad mayores, con una clara tendencia al alza desde el 74\% en el año 1985, hasta el $92 \%$ de 2014.

Finalmente, para el grupo de trabajadores más mayores (a partir de 45 ańos), la tasa de actividad disminuyó durante los últimos 80 y primeros 90 (desde valores del $37 \%$ hasta el $30 \%$ ), y un continuo aumento posterior hasta una tasa de actividad del $43 \%$ en 2014.

${ }^{6}$ Más adelante se trata específicamente el tema de la tasa actividad total de Gipuzkoa, ante la hipótesis de que tal vez sería diferente en caso de que se aplicaran medidas tendentes a la reducción de la jornada de trabajo con el objetivo de hacer disminuir la tasa de paro (Castrillón et al., 2016d). De todas formas el objetivo principal de este gráfico es reflejar la evolución de la tasa de actividad por grupos de edad. 
Figura 7

Tasa de actividad en Gipuzkoa, por grupos de edad

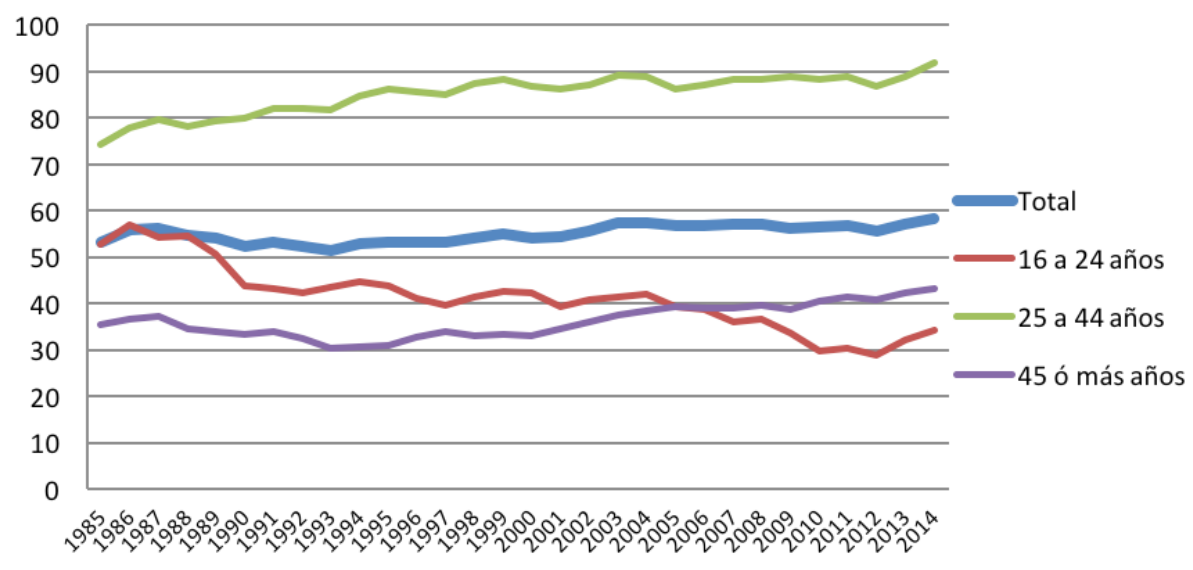

Fuente: Eustat.

Como puntos clave, podemos señalar que la tasa de actividad total ha aumentado algo en los últimos 25 ańos, con aumentos importantes para los grupos de edad de 25-44 años y mayores de 45 ańos, compensando estos grupos el continuo descenso de la tasa de actividad entre los más jóvenes, posiblemente debido a un incremento en el número de estudiantes. Se da el caso de que entre los más jóvenes también ha aumentado la tasa de actividad en los últimos años.

\subsection{Tasa de paro}

En cuanto a la tasa de paro, se observa en la Figura 8 que para el tramo de edad entre 25 y 44 años, esta tasa ha sido prácticamente la misma que para el conjunto de la población activa, mientras que los trabajadores de 45 o más años han tenido tasas de paro menores a la media, y al contrario, y de forma abultada sobre todo en los periodos con mayores tasas de paro, la tasa entre los más jóvenes ha sido mucho mayor a la media. Únicamente en los años en los que la tasa de paro estaban en torno al 5\%, los jóvenes entre 16 y 24 ańos sufrían tasas de paro cercanas a dicho número, pero a partir de 2007 (tal y como ocurría en los años anteriores) han sido los jóvenes los que más han padecido la falta de empleo.

En el último años contemplado (2014) la tasa de paro en Gipuzkoa estaba en torno al $12,5 \%$, y por grupos de edad esta tasa se distribuía de la siguiente manera: 32,6\% en el grupo de trabajadores entre 16 y 24 años, 13,6\% en el tramo de 25 a 44 ańos y 8,8\% para los trabajadores de 45 años o más. 
Figura 8

Tasa de paro en Gipuzkoa, por grupos de edad

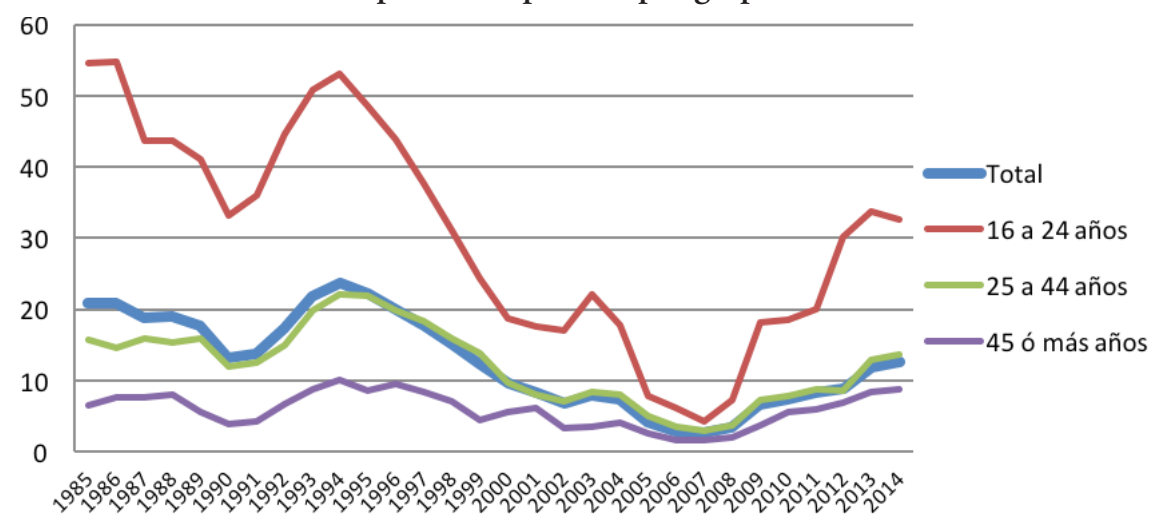

Fuente: Eustat.

\section{Envejecimiento de la población}

\section{1. Índice de reemplazo}

Se conoce como índice de reemplazo al porcentaje de personas residentes con edades entre 15 y 24 ańos, sobre el total de personas con edades entre 55 y 64 años.

Figura 9

Índice de reemplazo (Gipuzkoa, España), 2002-2014

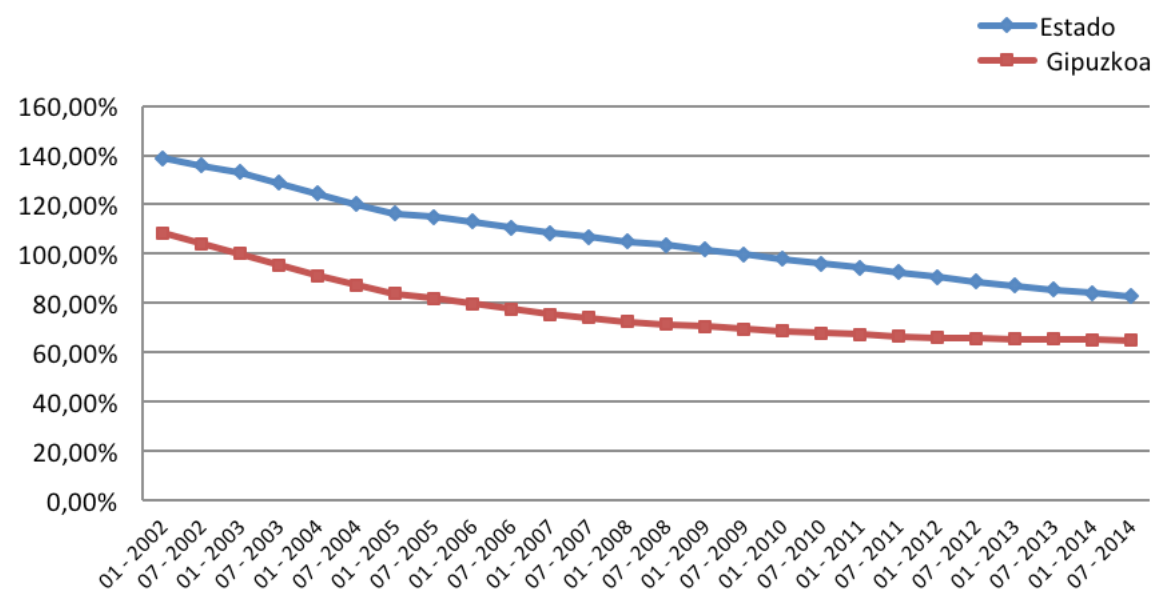

Fuente: INE. 
En la Figura 9 hemos recogido este ratio para los casos de Gipuzkoa y del España, entre los años 2002 y 2014.

Cada vez es menor, más en Gipuzkoa que en el España, el número de jóvenes que se pueden incorporar al mercado de trabajo sobre el número de personas que están cerca de la jubilación. Si en 2002 eran más las personas del primer grupo que las del segundo (108\% en Gipuzkoa y 139\% en España), tras un descenso continuo este porcentaje era del 65\% en Gipuzkoa y del 83\% en Espańa.

\subsection{Envejecimiento de la población activa}

Si consideramos la población activa a lo largo de distintos ańos, vemos cómo la edad de las personas trabajando o buscando empleo ha aumentado desde 2001 hasta 2011. En la siguiente ilustración (Figura 10) recogemos las diferentes curvas de edad que resultan para los tres años considerados.

\section{Figura 10}

Curva de edad de la población activa.

Gipuzkoa. 2001-2006-2011

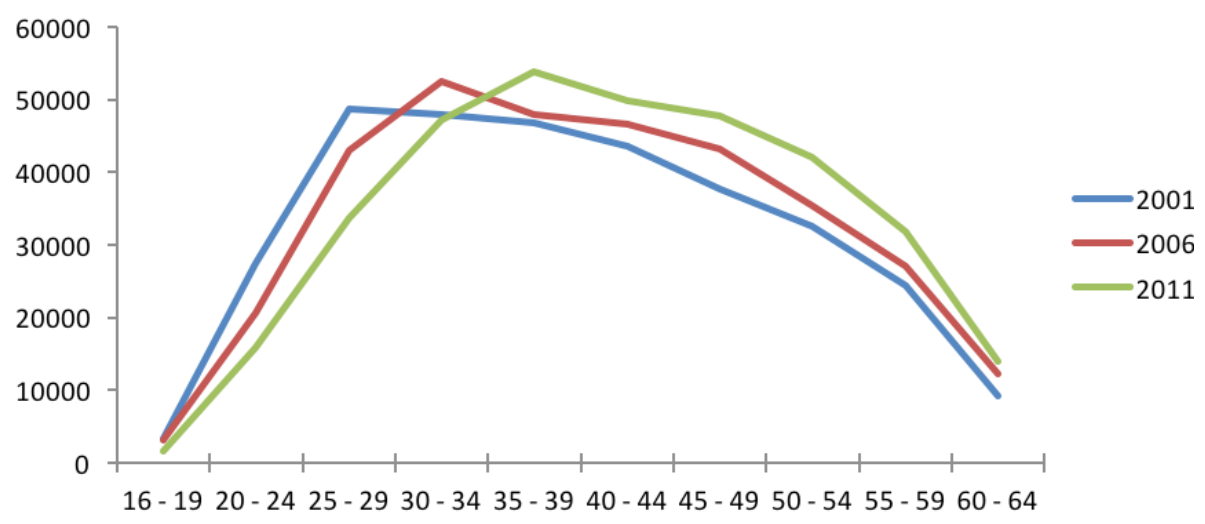

Fuente: elaboración propia a partir de datos de Eustat.

La curva de edad de la población activa se ha desplazado a la derecha cada lustro entre 2001 y 2011, de tal forma que este último año (curva verde) hay más activos en los grupos de edad de más de 35 años, frente a los que había en 2006 (curva roja), y antes, en 2001 (curva azul), mientras que en los grupos menores de 34 años ocurre lo contrario: en 2001 y en 2006 había más activos en estos grupos de edad que en 2011. 


\section{Trabajadores por cuenta propia, cooperativistas y trabajadores del sector público}

A continuación, comparamos el porcentaje de autónomos, cooperativistas y empleados públicos en Gipuzkoa y en España. El porcentaje de cooperativistas en Gipuzkoa, en torno al 5\%, es mucho mayor que en España, con un porcentaje ínfimo. De todas formas, cabe señalar el decrecimiento de este porcentaje entre los trabajadores guipuzcoanos, a pesar de la importancia que si

\section{Figura 11}

Porcentaje de autónomos, cooperativistas y trabajadores del sector público sobre el total de ocupados (Gipuzkoa)

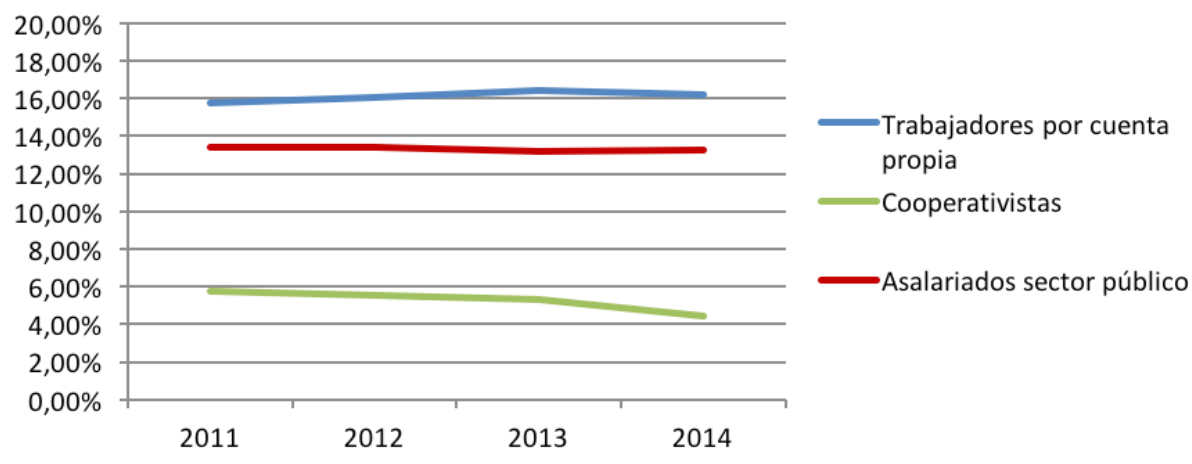

Fuente: Eustat.

Figura 12

Porcentaje de autónomos, cooperativistas y trabajadores del sector público sobre el total de ocupados (Espańa)

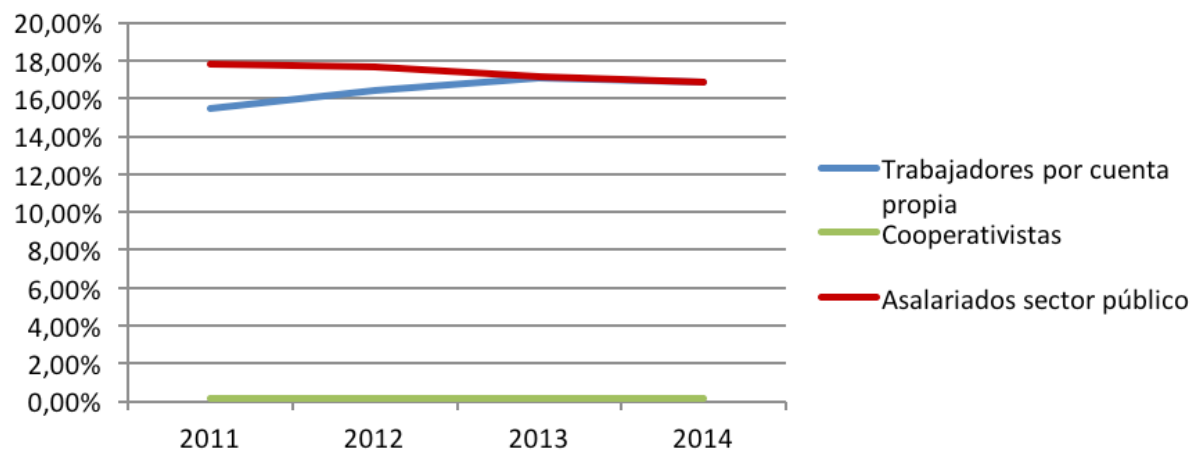

Fuente: INE. 
gue teniendo el cooperativismo en el territorio, con una larga tradición empresarial ampliamente estudiada (Mendizabal et al., 1995; Errasti, 2003; Azkarraga, 2006). El porcentaje de autónomos es similar en Gipuzkoa y en España, mientras que el porcentaje de empleados públicos es mucho mayor en España (en torno al $17 \%$, aunque con tendencia a la baja) que en Gipuzkoa, con niveles algo superiores al $13 \%$.

Esta distribución entre contratos públicos y privados tiene su importancia a la hora de implantar políticas de Reducción del Tiempo de Trabajo, en el sentido de que la administración puede jugar un papel como precursora y modelo en este tipo de inciativas (Imaz, 2006a; 2003).

\section{Población asalariada por tipo de contrato}

A continuación, mostramos la evolución de los tipos de contratos (fijos o temporales), en Gipuzkoa y en España, desde el año 2000 hasta el 2014.

Como es sabido, tras las últimas reformas de las leyes laborales, el número de contratos fijos ha disminuido debido a que casi toda la nueva contratación, a partir del estallido de la crisis, se realiza mediante contratos temporales. Esto hace que el número total de empleados con contrato fijo haya disminuido, tanto en Gipuzkoa como en España, a la vez que el número de trabajadores con contrato temporal ha aumentado. En 2014, la cuarta parte de los contratos vigentes en Gipuzkoa y en España, son contratos temporales.

Figura 13

Número de trabajadores fijos y temporales.

Gipuzkoa

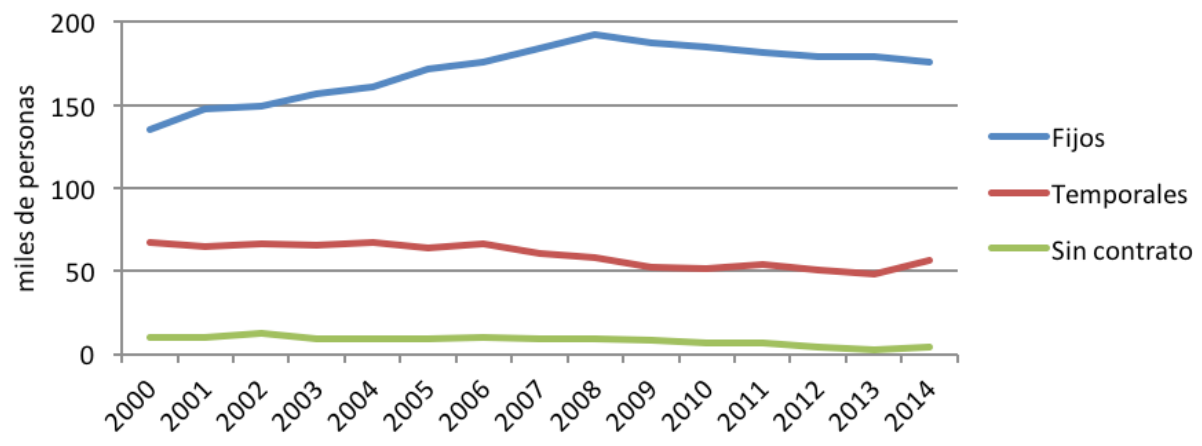

Fuente: Eustat. 
Figura 14

Porcentaje de trabajadores fijos y temporales.

Gipuzkoa

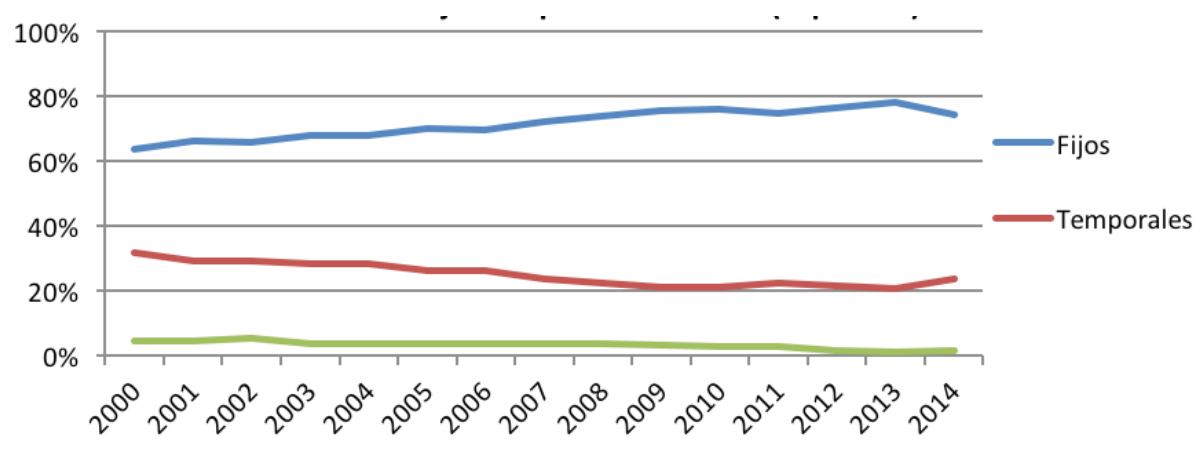

Fuente: Eustat.

Figura 15

Número de trabajadores fijos y temporales.

España

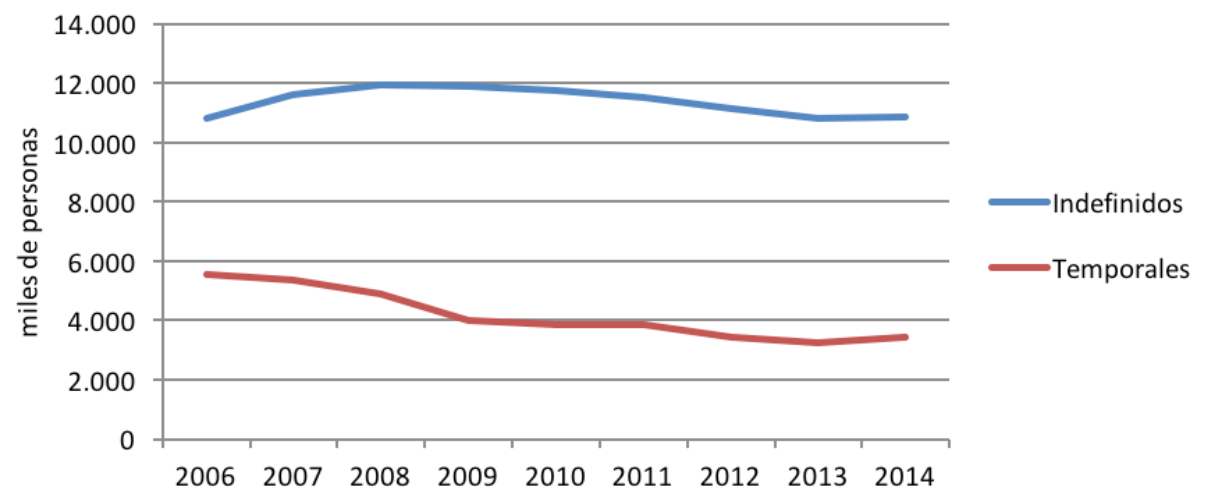

Fuente: INE. 
Figura 16

Porcentaje de trabajadores fijos y temporales.

España

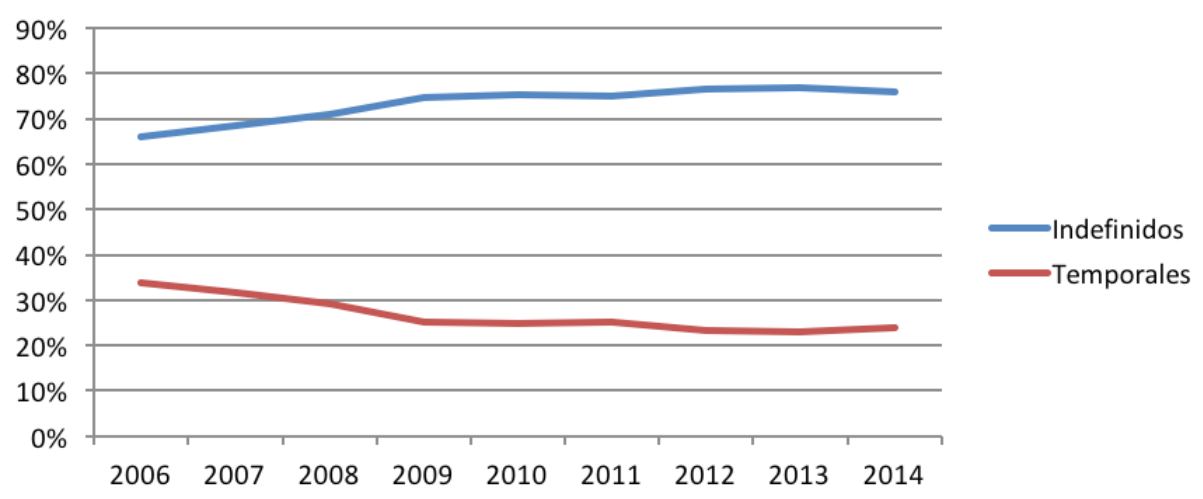

Fuente: INE.

\section{Diferencias entre mujeres y hombres en la actividad y el empleo}

La brecha entre los hombres y las mujeres es un hecho estructural y de marcado carácter estable en las relaciones de empleo de las economías capitalistas contemporáneas. En este apartado pretendemos aportar algunos elementos de análisis, en la línea de las desigualdades entre sexos que ya se vienen constatando desde hace décadas en las condiciones de empleo, especialmente en las actividades, los salarios y los tiempos de trabajo (Rodríguez y Larrañaga, 1999; Larrañaga, 2005).

\subsection{Tasas de actividad y paro}

La evolución de la tasa de actividad de mujeres y hombres de 16 y más años en Gipuzkoa entre 1985 y 2014 aparece reflejada en la Figura 17. Se observa que en los ańos 80 la tasa de actividad de los hombres superaba el $70 \%$ y que a lo largo del periodo ha disminuido hasta el 63\%, mientras que en el caso de las mujeres la evolución ha sido la contraria (tasa de actividad del 35\% en 1985, y del 53\% en 2014), lo que indica su creciente incorporación a la actividad laboral remunerada. La diferencia en la tasa de actividad entre hombres y mujeres se situaba en 30 puntos el año 1985, y esa diferencia se ha reducido hasta 9 puntos en 2014 . 
Figura 17

Tasa de actividad (mujeres, hombres),

Gipuzkoa, 1985-2014

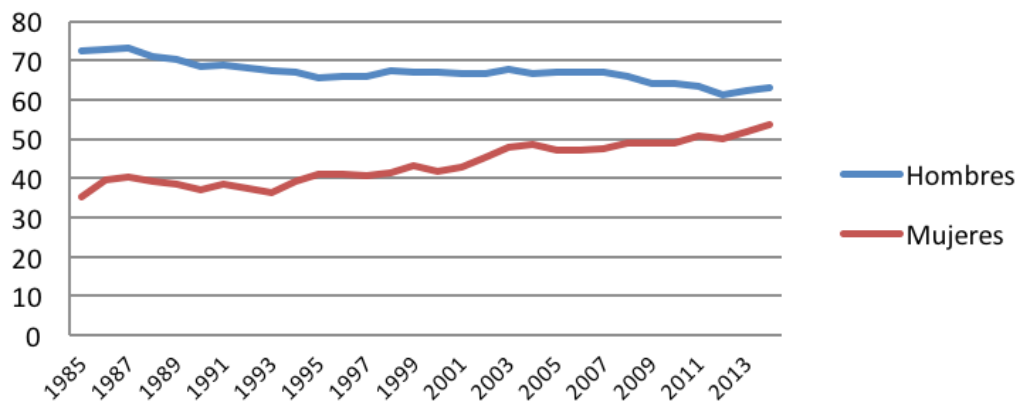

Fuente: Eustat.

En la Figura 18 se recoge a evolución de la tasa de paro de mujeres y hombres de 16 y más años en Gipuzkoa entre 1985 y 2014. En este caso se observa que la tasa de paro ha ido oscilando según los ciclos económicos, que para las mujeres dicha tasa era mucha mayor que para los hombres durante los primeros años del periodo considerado, que esa diferencia fue reduciéndose paulatinamente hasta 2007 en que para mujeres y hombres se igualó en torno al 3\%, y que a partir de 2007 la tasa de paro ha aumentado tanto en el caso de las mujeres como en el de los hombres de forma similar hasta alcanzar un 12,5\% en 2014.

Figura 18

Tasa de paro (mujeres, hombres),

Gipuzkoa, 1985-2014

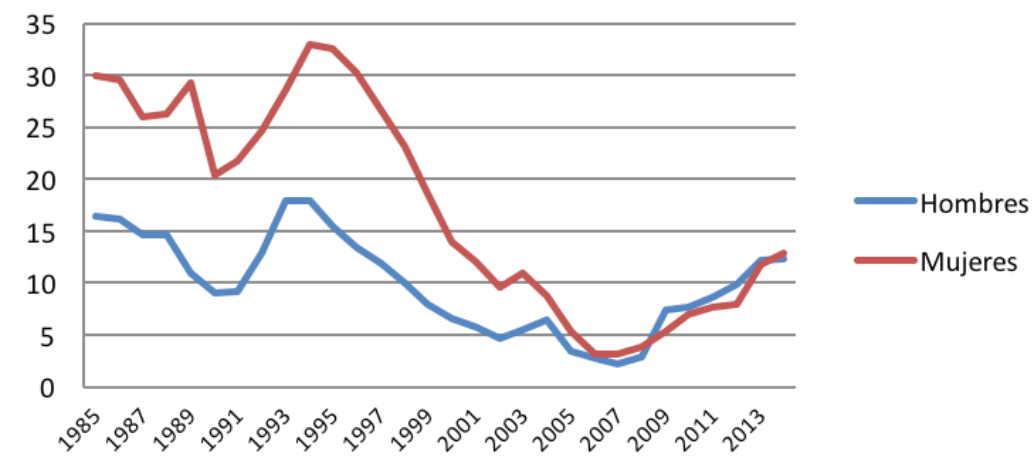

Fuente: Eustat. 


\subsection{Ganancia salarial}

Para el caso de los salarios hemos utilizado los datos correspondientes a la CAV aportados por la Encuesta Anual de Estructura Salarial del INE. Como ganancia salarial se hace referencia a los ingresos brutos por trabajo, que incluye el total de las percepciones salariales en dinero efectivo y remuneraciones en especie.

\section{Mediana y media}

La diferencia entre las medianas (Figura 19) y las medias aritméticas (Figura 20) de los salarios para hombres y mujeres se ha mantenido desde el inicio de la crisis. En 2013, la mediana salarial para las mujeres está en torno a $19.500 €$ (es decir, la mitad de las trabajadoras cobra menos que esa cantidad y la otra mitad, más), y la mediana salarial para los hombres, en dicho ańo, llega a los $27.400 €$ (un $40 \%$ más que las mujeres). En cuanto a la media aritmética de los salarios de mujeres y hombres (superior a la mediana, lo cual indica que los salarios superiores se alejan mucho de la media), estas cantidades eran de 22.600 y $30.300 €$, respectivamente.

Figura 19

Ganancia salarial (mediana).

CAV, 2008-2013

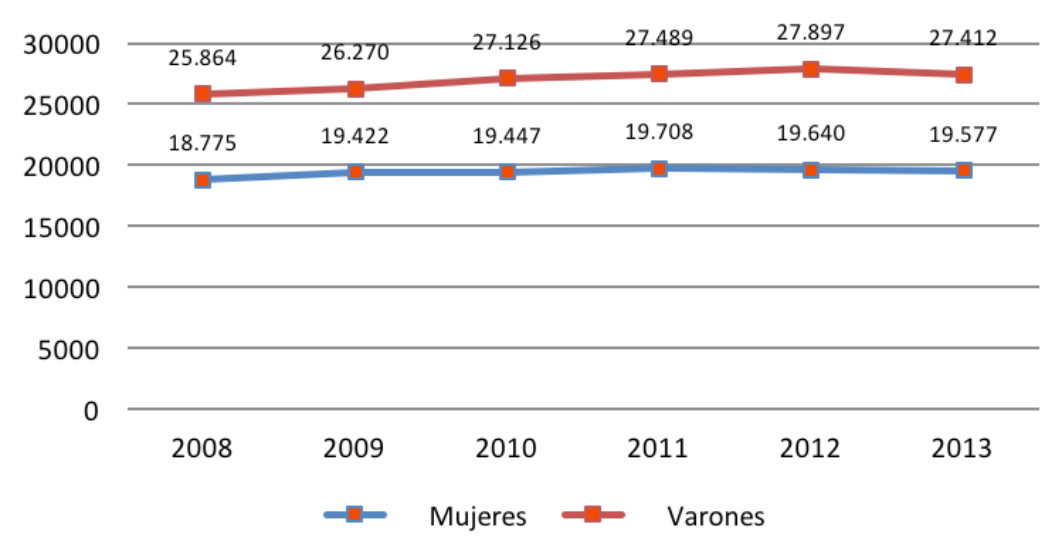

Fuente: INE. 
Figura 20

Ganancia salarial (media).

CAV, 2008-2013

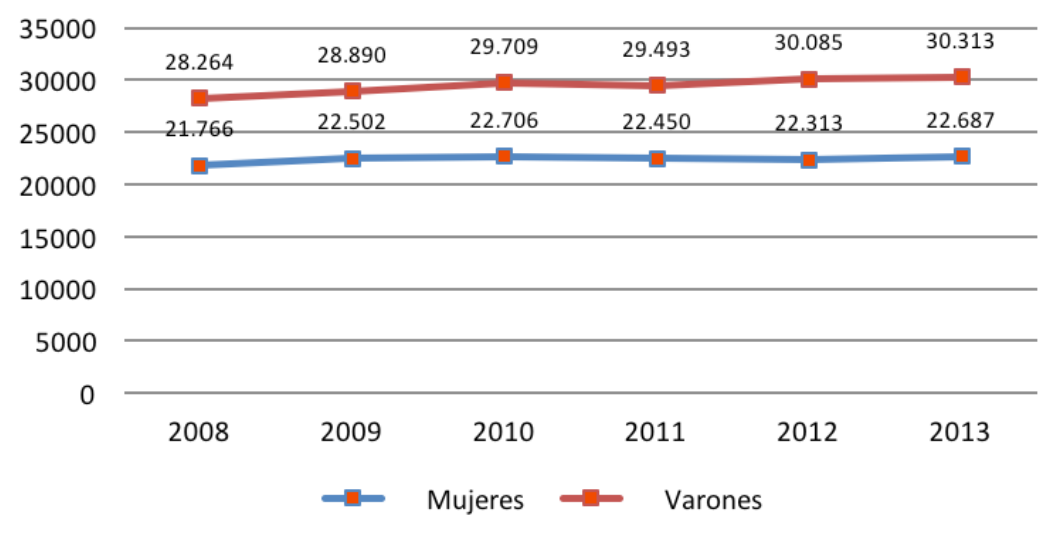

Fuente: INE.

\section{Percentiles 10 y 90}

Observando el percentil 10 (Figura 21), se observa que el 10\% de los hombres que menos cobra tenía en 2008 un salario inferior a $14.000 €$, mientras que para las mujeres ese umbral llegaba a $8.000 €$. Como «consuelo» para las mujeres, observamos que este umbral ha disminuido para los hombres desde que se inició la crisis (hasta los $12.000 €$ ) y sin embargo para las mujeres se ha mantenido, lo cual indica que la precarización ha aumentado más entre los hombres tendiendo a igualarse con la precarización salarial femenina, aunque todavía la brecha es significativa, siendo el percentil 10 de los hombres un 50\% mayor que el de las mujeres.

Para los salarios más altos también ocurre que los hombres cobran más (ver Figura 22, percentil 90), aunque relativamente la diferencia sea menor que para la mediana o para los salarios inferiores: el $10 \%$ de las mujeres que más gana recibe más de $41.100 €$ anuales, para $50.400 €$ de los hombres (un 22,6\% mayor que las mujeres). 
Figura 21

Ganancia salarial (percentil 10), CAV, 2008-2013

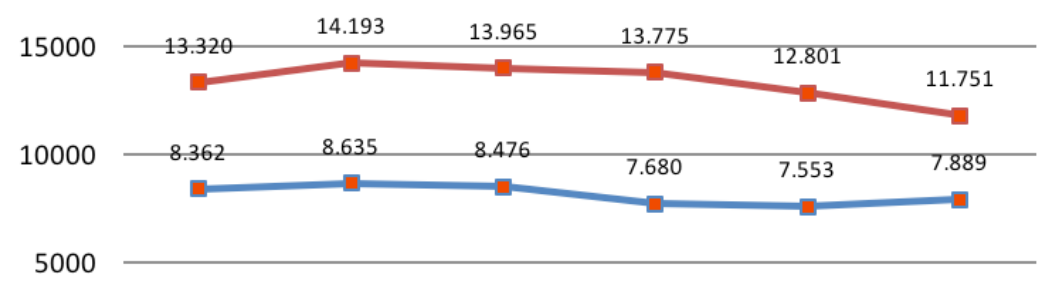

\section{0}

$\begin{array}{lrrrrr}2008 & 2009 & 2010 & 2011 & 2012 & 2013 \\ & - & \text { Mujeres } & - & & \text { Varones }\end{array}$

Fuente: INE.

Figura 22

Ganancia salarial (percentil 90).

CAV, 2008-2013

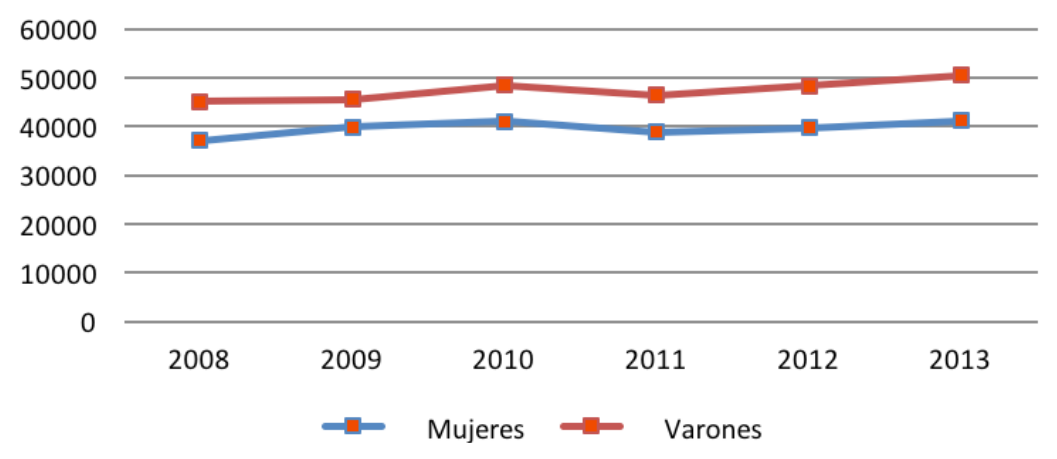

Fuente: INE.

\subsection{Estructura salarial por tipo de contrato}

Considerando los tipos de contrato según su duración, observamos que para los contratos de duración indefinida la ganancia media (Figura 23) es superior a la ganancia media de la población laboral en general que habíamos visto en la Figura 26, y ha aumentado ligeramente entre 2008 y 2013 tanto para mujeres como para hombres. Por otra parte, la diferencia entre mujeres y hombres se ha mantenido durante los últimos años, y el año 2013 la ganancia media de las mujeres con contratos indefinidos era de $23.800 €$, y la de los hombres, $32.700 €$. 
Figura 23

Ganancia salarial (media de contratos de duración indefinida).

CAV, 2008-2013

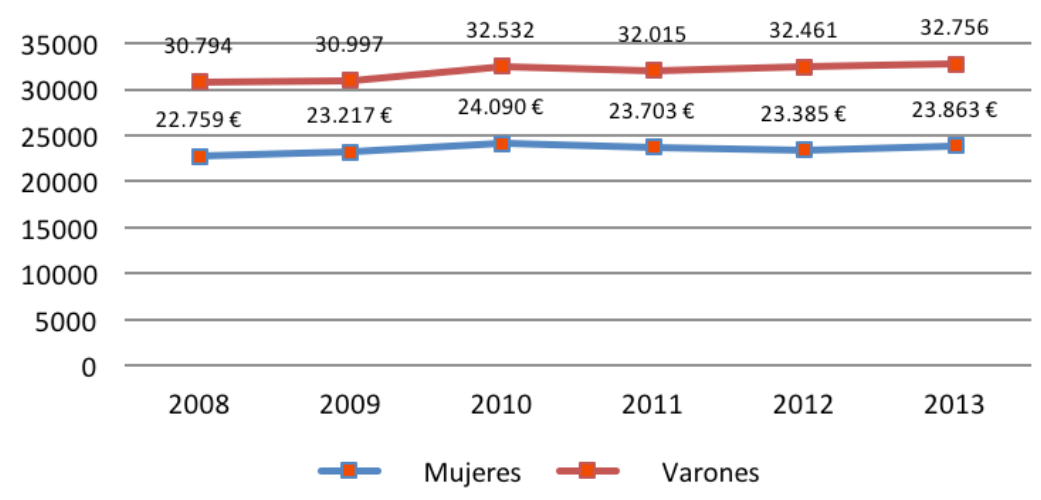

Fuente: INE.

Sin embargo, para los contratos de duración determinada, la evolución de los salarios medios ha ido a la baja desde 2009 hasta 2013 (Figura 24), quedando este último año en $17.900 €$ en el caso de las mujeres, y $18.600 €$ en el de los hombres.

Figura 24

Ganancia salarial (media de contratos de duración determinada). CAV, 2008-2013

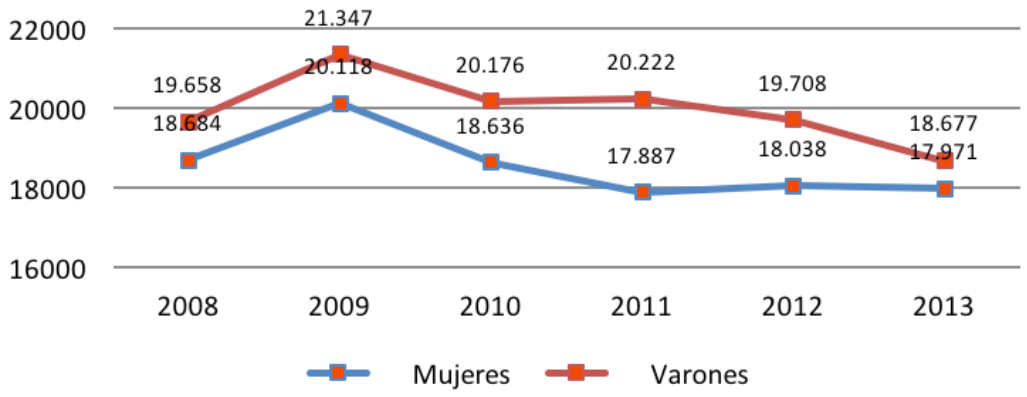

Fuente: INE. 


\subsection{Ocupados por tipo de jornada}

En las Figura 25 y Figura 26 observamos la evolución del número de trabajadoras y trabajadores (en miles) ocupados a jornada completa o a jornada parcial, lo que nos permite constatar que las dos tendencias más marcadas son la caída del empleo a tiempo completo de los hombres y el aumento del volumen de mujeres empleadas a tiempo parcial.

Figura 25

Número de trabajadores (miles) con jornada a tiempo completo.

CAV, 2002-2014

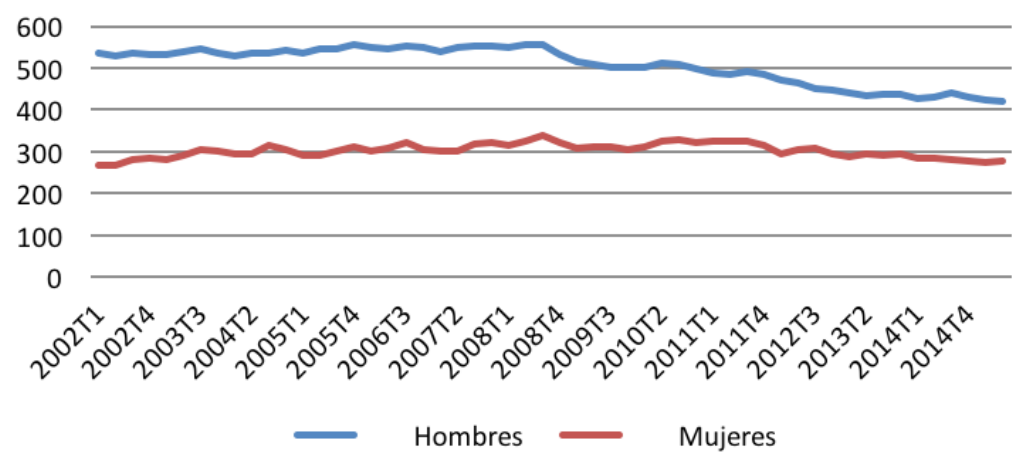

Fuente: INE.

Figura 26

Número de trabajadores (miles) con jornada a tiempo parcial.

CAV, 2002-2014

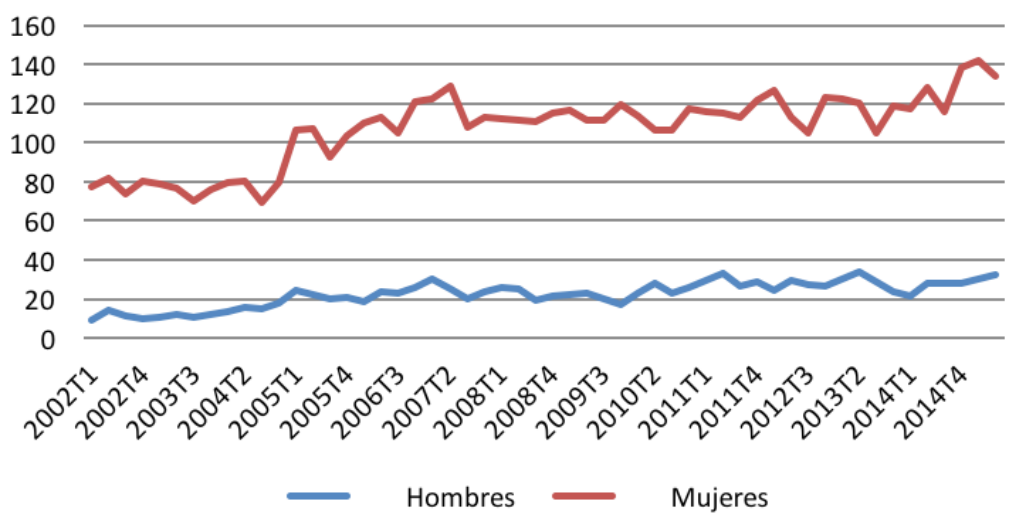

Fuente: INE. 


\subsection{Ocupados por tipo de contrato}

En las Figura 27, Figura 28 y Figura 29 se refleja la evolución del número de mujeres y hombres contratados (en miles), según el tipo de contrato dependiendo de su duración: indefinido fijo, temporal u otros contratos. Como indefinido fijo se considera un contrato «fijo o de duración indefinida, ya sea permanente a lo largo del tiempo o discontinuo", como temporal, un contrato «temporal, de aprendizaje, formación o prácticas, estacional o de temporada u otro tipo de temporal», y en otros contratos figuran "Sin contrato y otros no contemplados anteriormente». Como notas a destacar señalamos que las mujeres con contrato indefinido han aumentado considerablemente en el periodo considerado, pasando de 35.100 a 83.100 , en consonancia con los datos contemplados anteriormente y referidos a la incorporación laboral de la mujer, hasta acercarse a los 92.600 hombres con contrato indefinido que había en 2014. Para el caso de los contratos temporales no hay grandes diferencias entre la evolución de mujeres y hombres, y en el caso de Otros contratos (figura que según Eustat incluye a las personas ocupadas sin contrato) se observa que había un número considerable de mujeres en esta situación (13.400 en 1998, para una cantidad de 2.100 hombres ese año), que parece indicar la situación de precariedad de las mujeres trabajadoras, dentro de la economía no declarada, realizando mayormente trabajos de limpieza y asistencia domiciliaria. Es verdad, que según los datos proporcionados por Eustat, parece que en los últimos años este tipo de contratos ha disminuido, pero en 2014 todavía hay 3.400 mujeres en este apartado, para 900 hombres.

Figura 27

Población ocupada mayor de 16 ańos (miles), con contrato indefinido. Gipuzkoa, 1994-2014

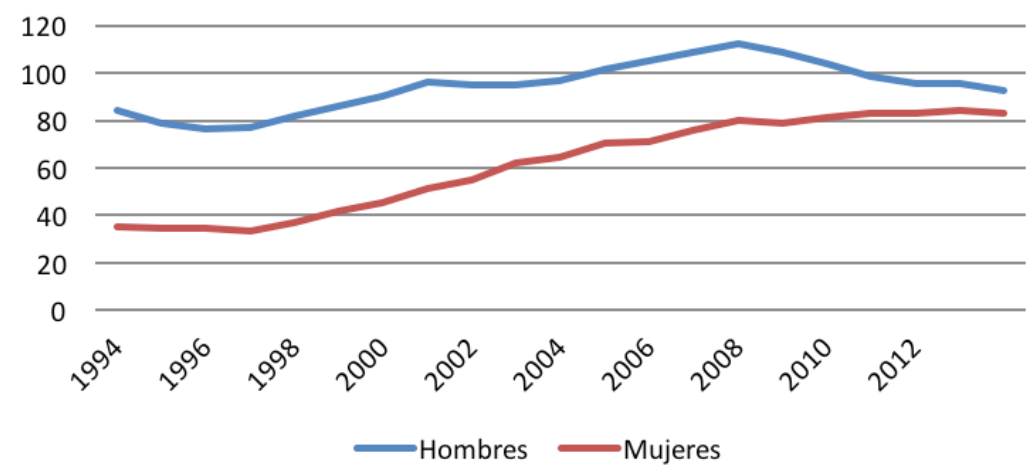

Fuente: Eustat. 
Figura 28

Población ocupada mayor de 16 años (miles), con contrato temporal.

Gipuzkoa, 1994-2014

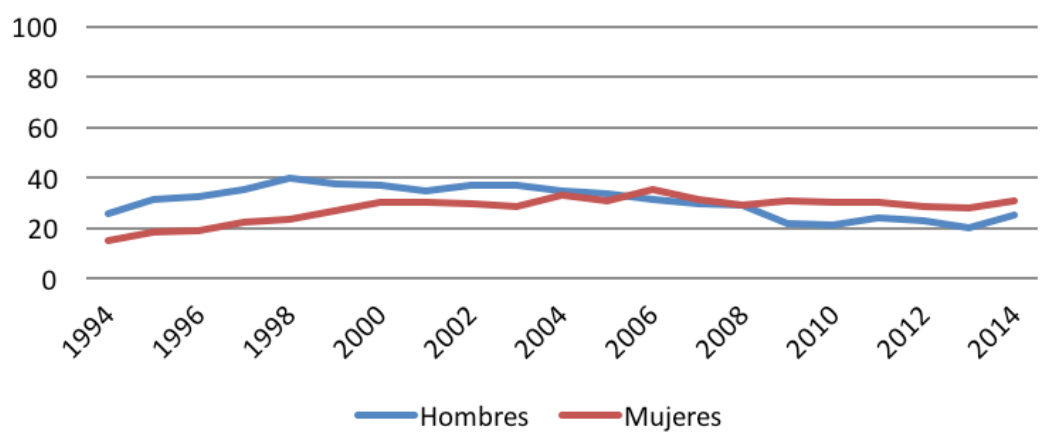

Fuente: Eustat.

Figura 29

Población ocupada mayor de 16 años (miles), con «Otros contratos». Gipuzkoa, 1994-2014

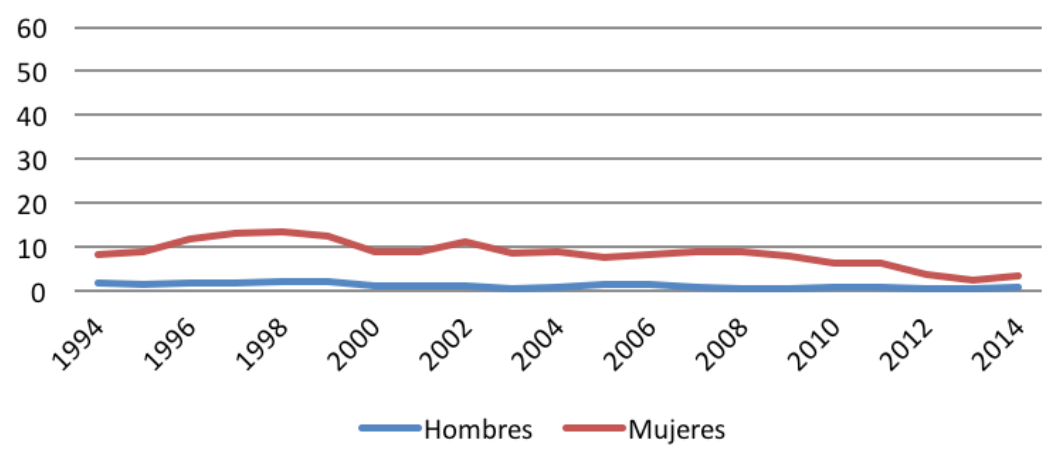

Fuente: Eustat.

\section{Variaciones en la tasa de actividad debidas al desempleo}

\subsection{Introducción. Definiciones}

En este apartado vamos a analizar la hipótesis de que el aumento del desempleo como consecuencia de la crisis económica ha provocado el abandono de la búsqueda de trabajo remunerado para un número considerable de personas que 
podríamos definir como "desanimadas», es decir, personas que han perdido la confianza en encontrar un puesto de trabajo y han dejado de buscar un empleo, por lo que han pasado de ser consideradas como desempleadas, a ser consideradas como inactivas. El resultado, como veremos, es que la información disponible no permite afirmar que dicha hipótesis sea cierta, lo que vendría a suponer que una reducción drástica del desempleo no asegura que vaya a aumentar la tasa de actividad de forma considerable.

Definiciones: La tasa de actividad se calcula como:

— (ocupados + parados)/población mayor de 16 años (INE),

— (ocupados + parados)/población en edad de trabajar (16-64) (Eustat, Eurostat).

\subsection{Comparando con los años anteriores al comienzo de la crisis}

Con los datos de personas ocupadas y personas buscando empleo obtenemos la tasa de actividad, que nos indica el porcentaje de personas que trabajan o quieren trabajar, sobre el total de la población mayor de 16 años, según la definición del INE. La evolución de dicha tasa en los últimos años (datos trimestrales) en Gipuzkoa ha sido la indicada en la siguiente figura:

Figura 30

Tasa de actividad en Gipuzkoa, 2002-2014

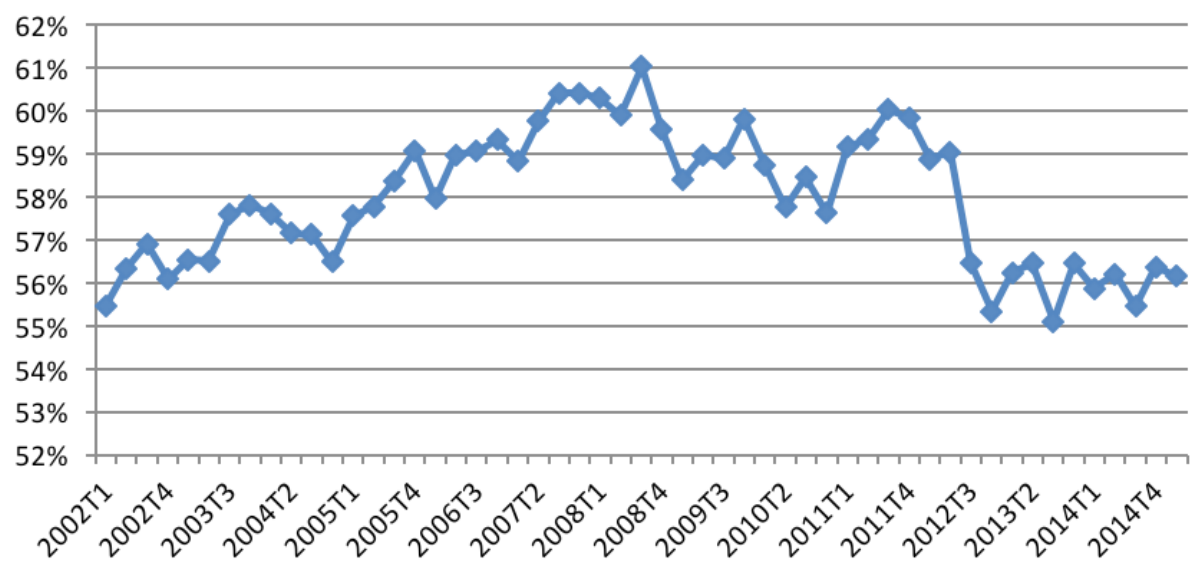

Fuente: elaboración propia a partir de datos del INE.

Resulta evidente que mientras descendía la tasa de paro porque la situación económica generaba nuevos empleos y consolidaba los existentes, la tasa de ac- 
tividad iba creciendo, es decir, la suma de los porcentajes de personas ocupadas y paradas iba en aumento. Sin embargo, a partir del año 2008 la crisis golpea el tejido productivo, el número de parados (y la tasa de paro) comienzan a aumentar y ello lleva a un número considerable de personas a abandonar la búsqueda de empleo, descendiendo la tasa de actividad desde un 61\% hasta el 56\% a inicios de 2015 .

Figura 31

Relación entre la tasa de actividad y la tasa de paro en Gipuzkoa, 2002-2015

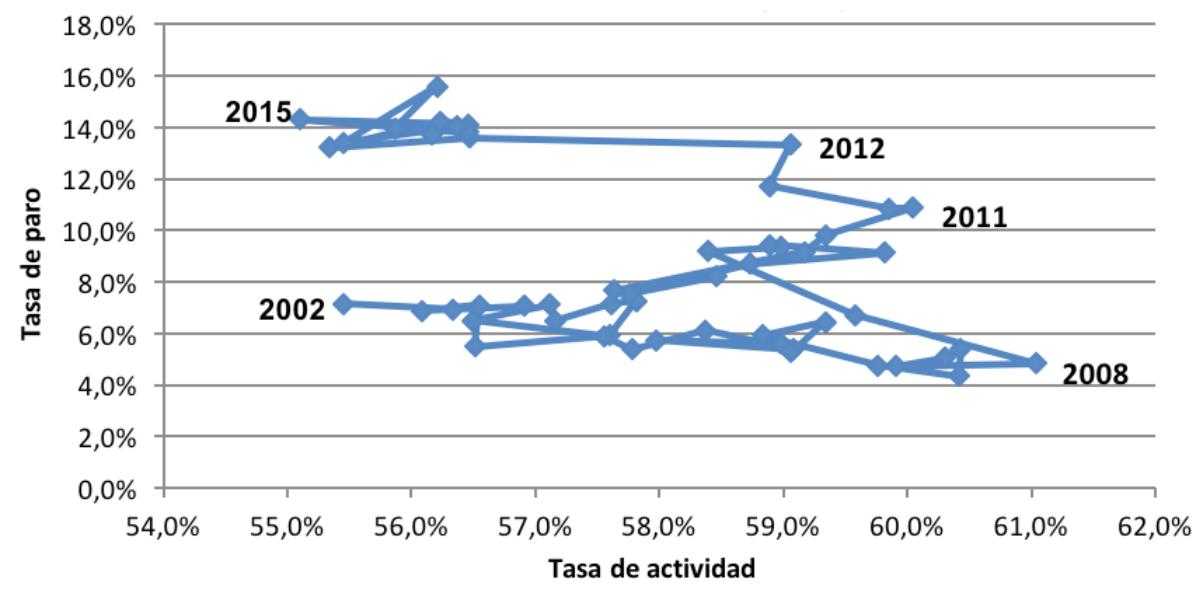

Fuente: INE.

Esta relación se puede observar mejor en la a inicios de 2015.

Figura 31. En el año 2002 la tasa de paro en Gipuzkoa rondaba el 7\%, con una tasa de actividad en torno al 55,5\%. A medida que fue descendiendo el paro, hasta llegar a una tasa cercana al 4\%, la tasa de actividad fue creciendo, esto es, el número de trabajadores ocupados o dispuestos a trabajar aumentó hasta llegar a un 61\% de la población en edad de trabajar. A partir de 2008, sin embargo, comienza a notarse el efecto de la crisis y la tasa de paro comienza a aumentar, hasta superar el 15\%, y a su vez, la tasa de actividad vuelve a reducirse hasta retroceder de nuevo al $55 \%$.

Si en el momento actual la tasa de actividad se recuperase hasta el máximo registrado del $61 \%$, eso significaría que 28.400 personas se sumarían a las 330.300 que actualmente figuran como activas —ocupadas o no-, es decir, que dejarían de ser inactivas "desanimadas». De todas formas hay que tener en cuenta que la tasa de actividad está calculada sobre el total de personas mayores 
de 16 ańos, con lo que el envejecimiento de la población provoca por sí mismo un descenso de dicha tasa, por lo que no parece probable que para el mismo nivel de actividad económica la tasa de actividad laboral se recuperase hasta alcanzar el 61\%. En este sentido, las tasas de actividad para la población en edad de trabajar (16-64 años) y para la población de 16 años y más son las siguientes (medias anuales entre 2002 y 2014):

\section{Figura 32}

Tasa de actividad en Gipuzkoa, para la población entre 15 y 64 años, y para la población de más de 16 años

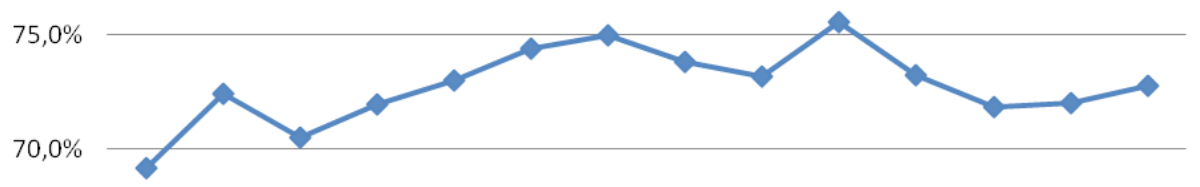

$65,0 \%$

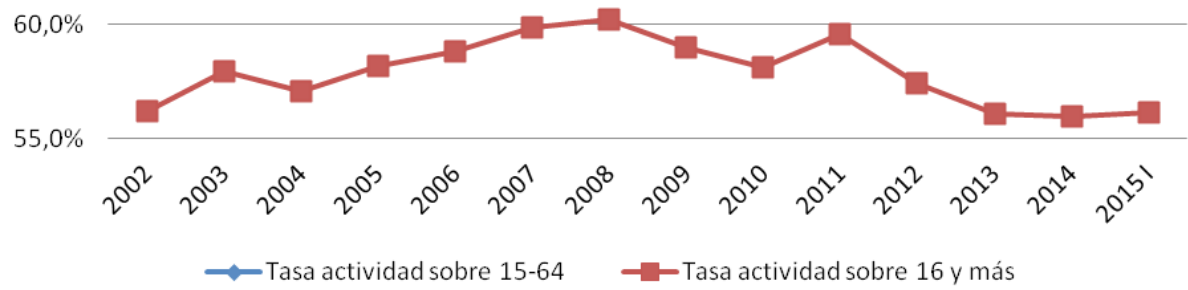

Fuente: elaboración propia con datos de Eustat y del INE.

En este caso vemos que entre los ańos 2011 y 2015 la tasa de actividad se ha reducido teniendo en cuenta a toda la población mayor de 16 años, y también se ha reducido, pero con cierta recuperación en los últimos dos años, si consideramos solo las personas entre 16 y 64 años.

Para esta serie, en el caso de que se volviese a repetir el valor máximo de la tasa de actividad de las personas en edad de trabajar (75,5\% en 2011) se obtiene que 12.400 personas actualmente «desanimadas» se reincorporarían a las relaciones laborales y pasarían, en caso de no encontrar ocupación, a ser de nuevo contabilizadas como paradas, aumentando por tanto considerablemente la tasa de paro. 


\subsection{Comparando con Europa (regiones de similar renta por habitante)}

Por otra parte, según los datos del Eurostat, la tasa de actividad de la CAV (no hay datos para Gipuzkoa) referida a la población en edad de trabajar (entre los 16 y los 64 años) es del 74\% en el año 2014. Para las regiones europeas con un nivel de PIB por habitante similar al de la $\mathrm{CAV}^{7}$, tenemos que en cuanto a las regiones comparables de la Unión Europea, la tasa de actividad varía entre el 69\% del Veneto hasta el 80,9\% de la Alta Baviera.

Figura 33

Tasa de actividad en las regiones europeas con un PIB/habitante similar al del País Vasco, 2014

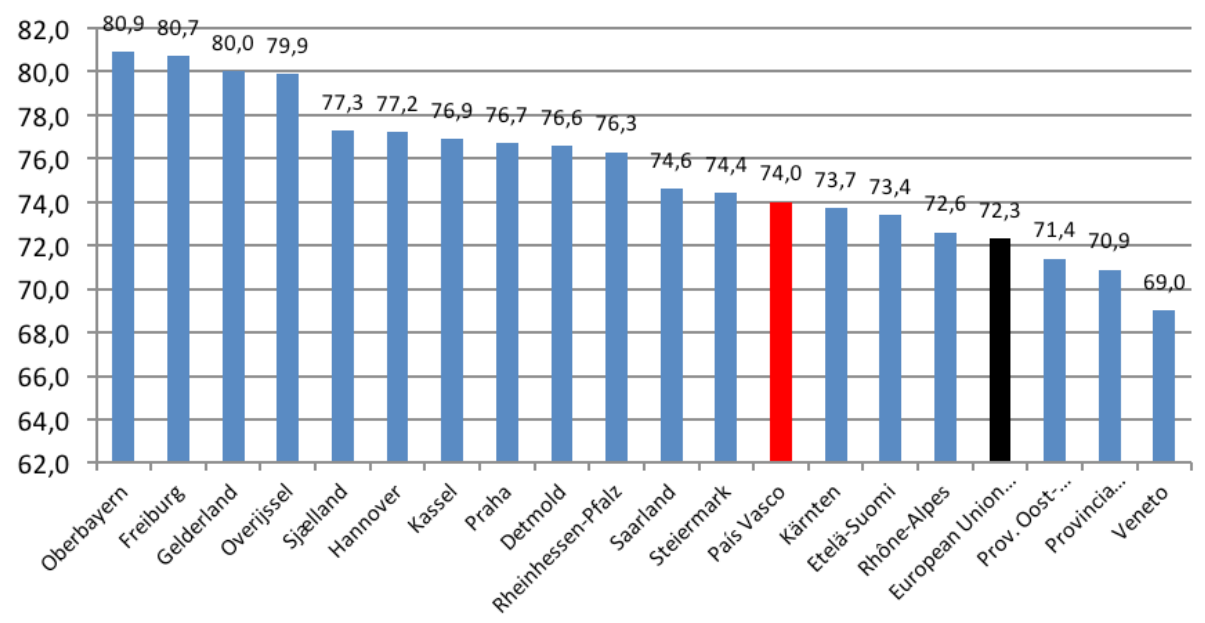

Fuente: elaboración propia a partir de datos de Eurostat.

Si la tasa de actividad en el País Vasco fuera alcanzara un valor medio del $75 \%$ de las regiones con una renta comparable, ello supondría la incorporación de 4.500 personas desanimadas a la búsqueda de empleo u ocupación.

De todas formas, para las 18 regiones europeas con renta per capita similar a la vasca, la tasa de paro oscila entre el 2 y el $10 \%$, claramente inferior a la tasa del 16\% de la CAV. Si la generación de nuevos empleos consiguiera absorber a la mitad de los parados, y se llegase a una tasa de paro del $8 \%$, homologable a la de las regiones europeas con igual renta, no parece deducirse de estos datos que la tasa de actividad aumentara considerablemente, es decir, que un gran número de personas que ahora son inactivas comenzaran a buscar un empleo.

7 La CAV tiene un índice de PIB/habitante de 122 con respecto al valor medio de la UE28=100, en las regiones que se citan dicho valor oscila entre 120 y 125 . 
Figura 34

Tasas de actividad y paro en regiones europeas con rpc similar a la CAV

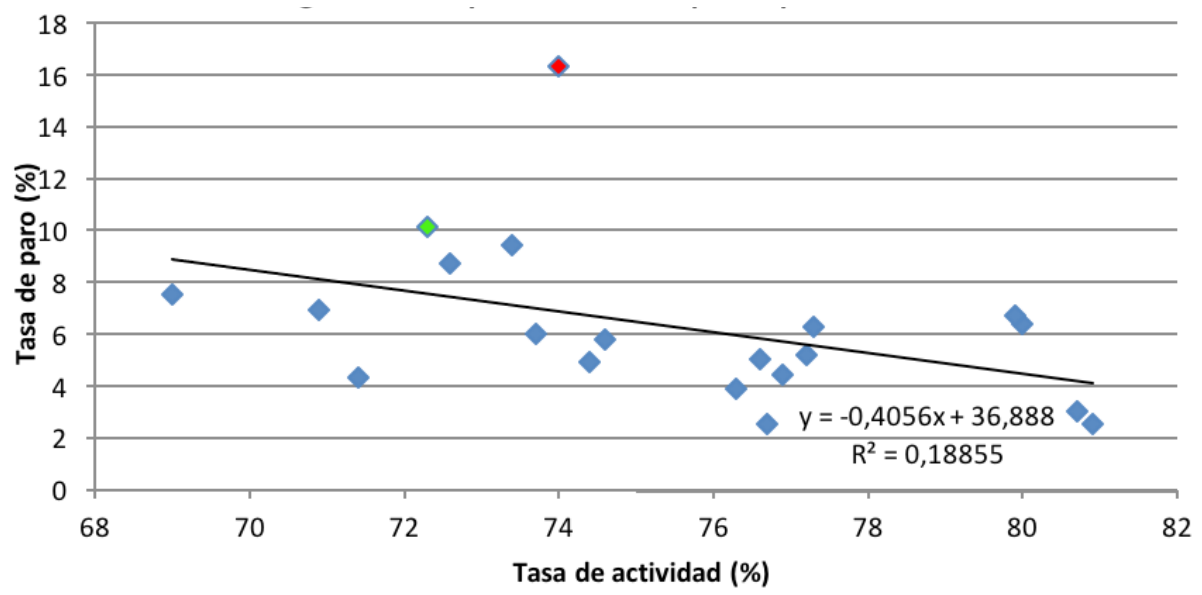

Nota: el punto rojo corresponde a la CAV, y el punto verde a la media EU28.

Fuente: elaboración propia con datos de Eurostat (regresión lineal sin el dato de la CAV).

Figura 35

Tasas de actividad y paro en regiones europeas con rpc similar a la CAV.

Regresión lineal

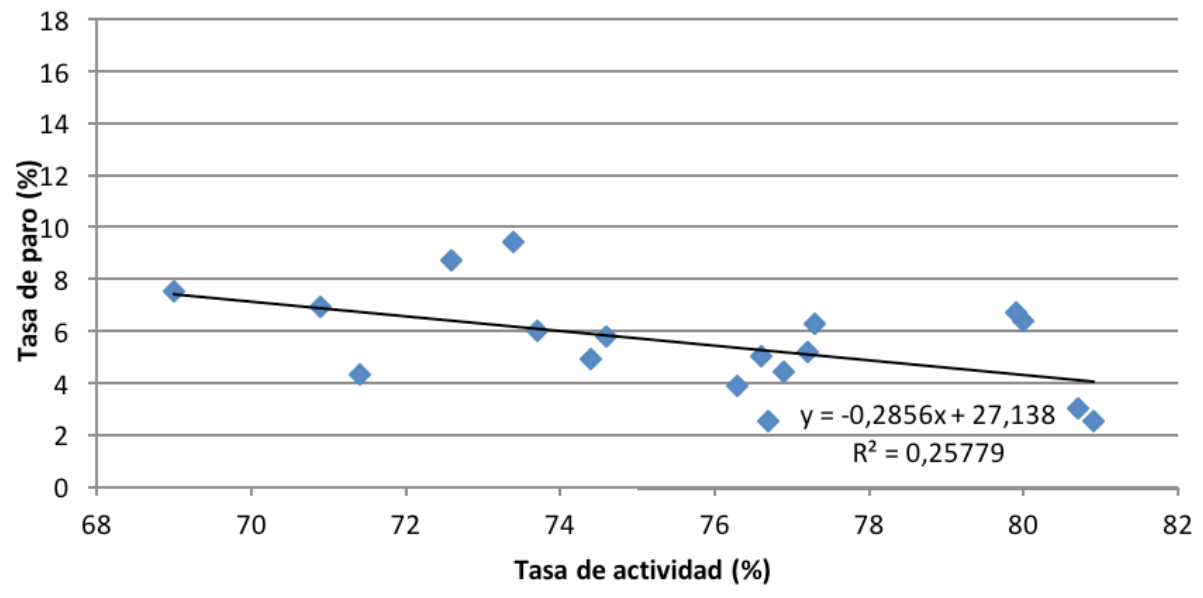

Nota: regresión lineal sin los datos de la CAV y la media EU28.

Fuente: elaboración propia con datos de Eurostat. 
La regresión lineal (sin el dato de la CAV ni el de la media EU28) que relaciona la tasa de actividad con la tasa de paro en regiones europeas con niveles de renta similares a la CAV no indica una relación fuerte entre dichas variables: aunque tiene una tendencia decreciente no hace suponer que una reducción sustancial del nivel de paro provocaría incrementos considerables en la tasa de actividad.

\subsection{Por regiones europeas de similar nivel de industrialización}

En la CAV el número de empleados en la industria (excluida la construcción) sobre el total de empleados es del 20,19\%. Haciendo la comparación con regiones europeas de similar nivel de industrialización (empleo industrial entre el 18 y el 22\%), obtenemos la siguiente figura, según la cual tampoco parece que la tasa de actividad resulta mucho mayor que la de la CAV.

\section{Figura 36}

Tasas de actividad en regiones europeas con niveles de industrialización similares a los de la CAV

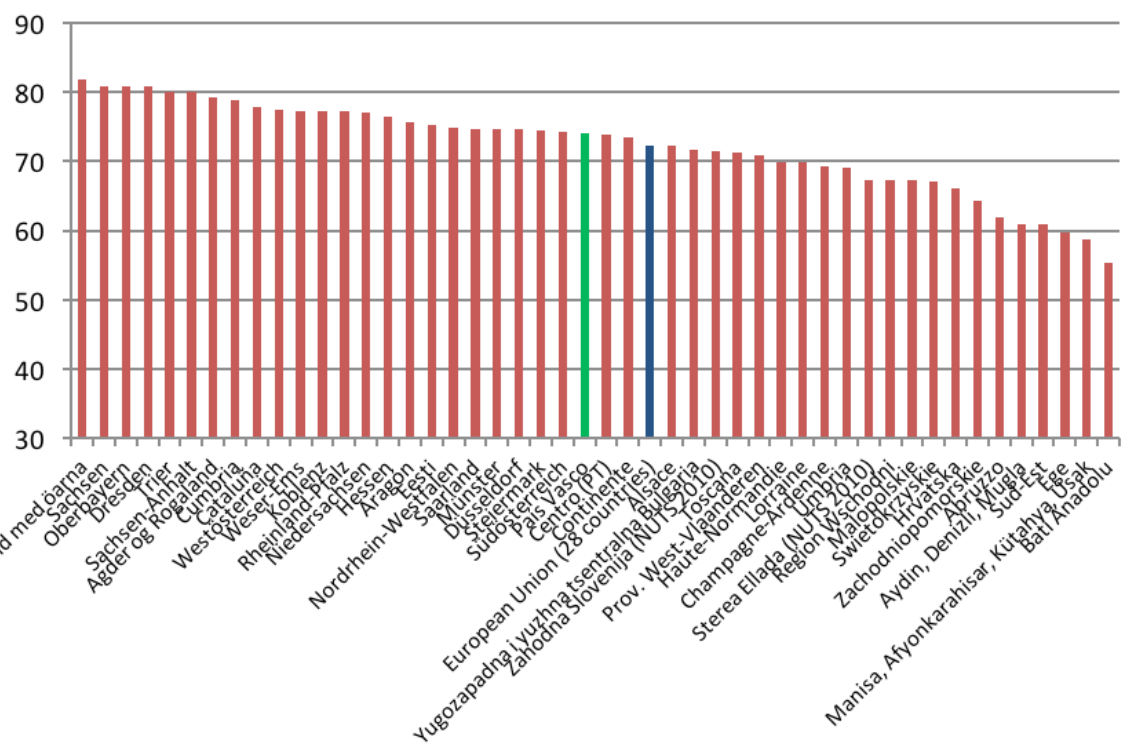

Fuente: elaboración propia con datos de Eurostat. 


\subsection{Tasa de actividad: conclusión}

Teniendo una perspectiva temporal, parece que en Gipuzkoa la tasa de actividad aumentaría en caso de recuperación económica, con un aumento potencial del empleo que debería ser capaz de atraer a un gran número de parados actuales (entre 12.400 y 28.400, según la tasa de actividad considerada).

Sin embargo, comparando con regiones europeas de renta o industrialización similar en el momento actual pero con una tasa de paro considerablemente inferior, no parece que la tasa de actividad sea mucho mayor que la vasca en dichas regiones.

\section{Jornada laboral de los asalariados en Gipuzkoa}

\subsection{Presentación. Definiciones}

Todos los datos de las siguientes tablas y gráficos están tomados del Eustat, por lo que vamos a tener en cuenta las definiciones que usa el Eustat ${ }^{8}$ :

Los puestos de trabajo equivalentes a tiempo completo (PTETC) se obtienen como «el total de horas trabajadas dividido por la media anual de las horas trabajadas en puestos de trabajo a tiempo completo en el territorio económico".

Se entiende por horas trabajadas «el número total de horas efectivamente trabajadas por el personal ocupado durante el año». Estas horas comprenden, siguiendo con la definición:

— Las horas trabajadas, normales y extraordinarias.

- La duración, en el lugar de trabajo, de tiempos muertos a causa de la falta ocasional de trabajo.

- El tiempo que corresponde a cortos períodos de descanso en el lugar de trabajo.

Se excluyen de las horas trabajadas:

- Las horas pagadas pero no trabajadas, como vacaciones anuales pagadas, días festivos pagados, o bajas por enfermedad.

- Interrupciones para comidas.

\footnotetext{
${ }^{8}$ Estas definiciones se pueden obtener en la página del Instituto Vasco de Estadística (Eustat): www.eustat.es
} 


\subsection{Jornada laboral anual (PTETC)}

Por lo tanto, si dividimos el número total de horas trabajadas entre los puestos de trabajo ETC, obtenemos la jornada media de un puesto a tiempo completo, o jornada laboral media anual. La evolución de esta jornada media entre el año 1995 y el año 2012 ha sido la siguiente, para el conjunto de los asalariados de Gipuzkoa:

Figura 37

Jornada anual de un asalariado a Tiempo Completo (1995-2012)

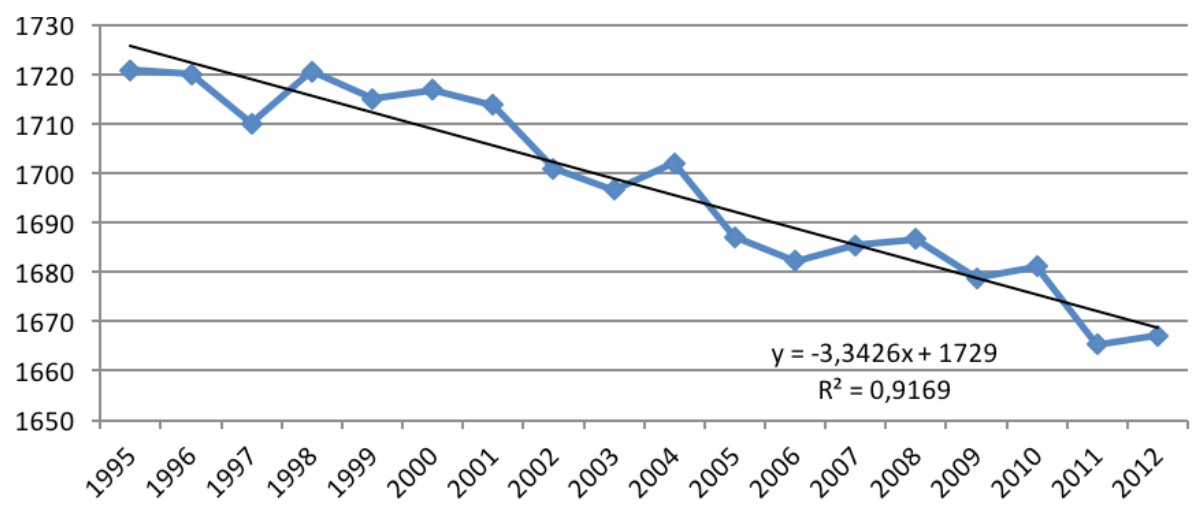

Fuente: elaboración propia, con datos de Eustat.

La regresión lineal tiene un coeficiente $\mathrm{R} 2=0.9169$, lo que hace que se ajuste bien a la evolución de los datos. Ello significa, entre otras cosas, que cada año la jornada laboral media de los asalariados disminuye en 3,34 horas, es decir, 33 horas y media cada década. Durante el periodo de 18 ańos, por tanto, la jornada laboral media de los asalariados de Gipuzkoa se ha reducido un 3,1\%, pasando de 1.720 horas a 1.667 horas anuales?

9 Imaz (2006b: 10) señalaba que para 2005 la jornada anual media en Euskadi era de1.700 horas, inferior a la espańola (1.750), a la de los nuevos estados del este europeo recién ingresados en la UE (1.800) o a las de los EE.UU., Japón y la media europea (1.800-1.900). Para una aproximación más extensa ver Imaz (2006a; 2003) 


\subsection{Jornadas anuales, por sectores}

Por sectores, las jornadas anuales de los asalariados se distribuyen según el siguiente gráfico:

\section{Figura 38}

Jornada anual de un asalariado a TC, por sectores (2012)

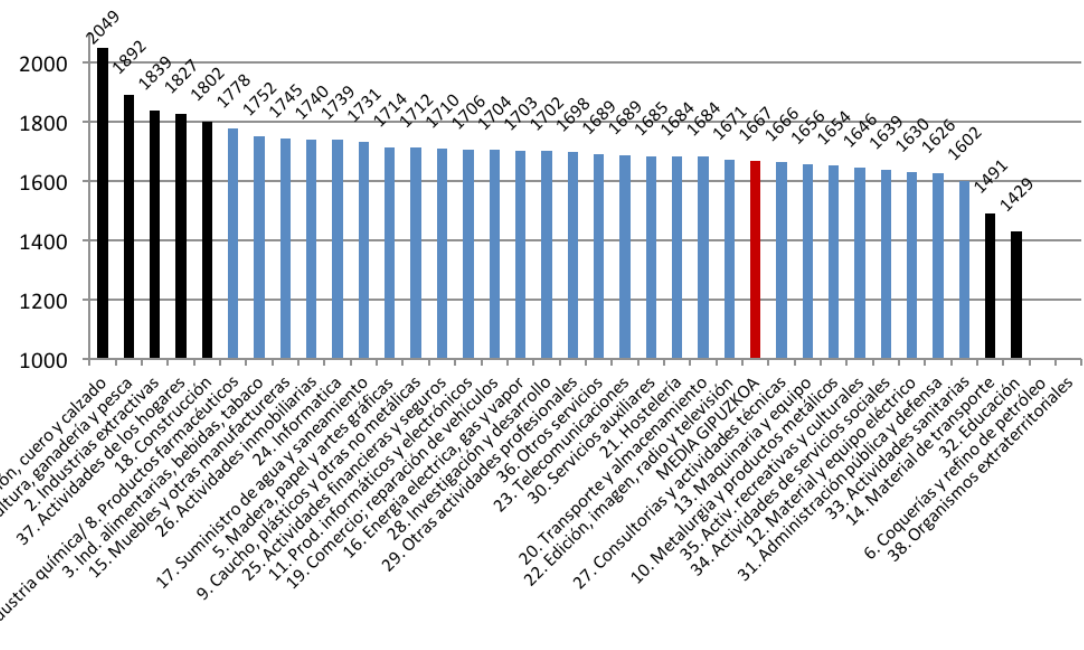

Fuente: elaboración propia, con datos de Eustat.

En la Figura 38, la columna en rojo nos muestra la jornada anula media de los asalariados guipuzcoanos (1.667 horas trabajadas durante el año), y las columnas en negro corresponden a las jornadas anuales con una desviación con respecto a la media mayor que la desviación típica (93 horas por año). El rango de jornadas anuales con una desviación con respecto a la media menor a la desviación típica, queda por tanto entre 1.574 y 1.760 horas, correspondientes a los sectores señalados con columnas azules.

\subsection{Jornadas anuales, por sectores relevantes}

Si tomamos los sectores en los que se han trabajado más de un 3\% del total de horas asalariadas, nos quedamos con los datos de los siguientes $13 \mathrm{sec}-$ tores: 
Figura 39

Jornada anual asalariado TC,

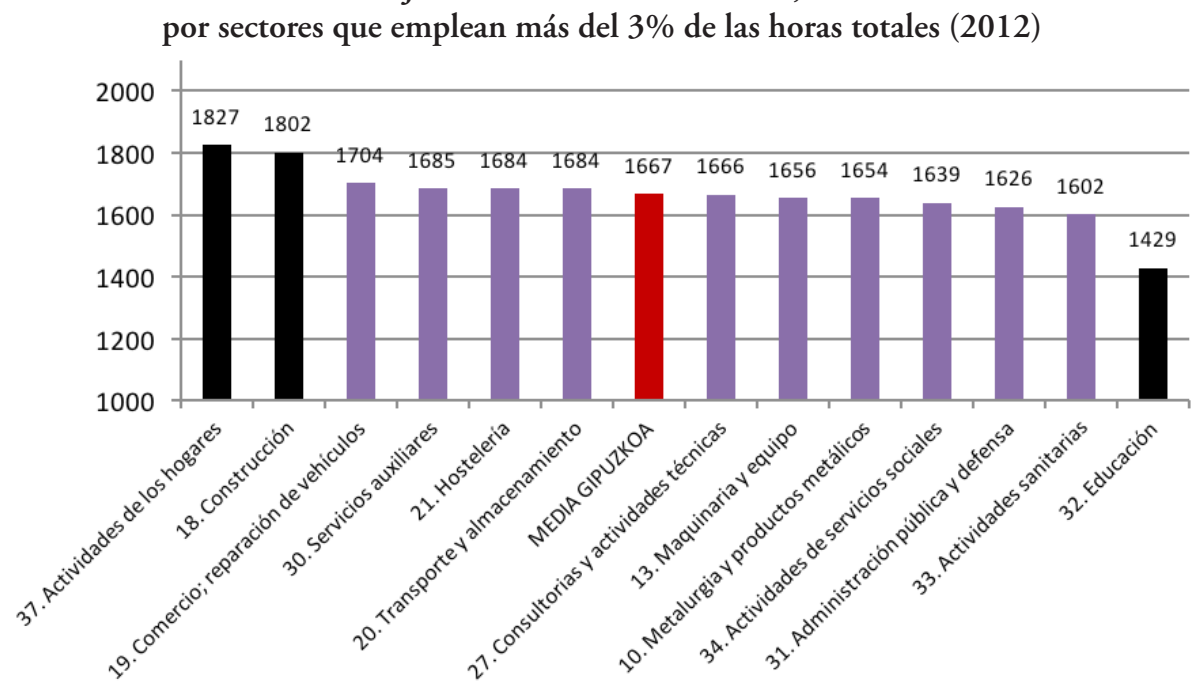

Fuente: elaboración propia, con datos de Eustat.

En estos 13 sectores se han cubierto en 2012 el 75\% del total de horas trabajadas por asalariados. Los sectores relevantes con jornadas laborales más amplias son las Actividades del hogar y la Construcción, con una desviación considerable con respecto a la media. En el lado opuesto, la jornada laboral más reducida corresponde a Educación, con una desviación de 238 horas anuales con respecto a la media.

El mayor porcentaje de horas asalariadas trabajadas en estos 13 sectores corresponde al del Comercio y reparación de vehículos (13,18\%), y a continuación están Metalurgia (9,69\%), y le siguen Administración pública, Educación y Construcción (entre el 6 y 7\%), Hostelería y Maquinaria (entre el 5 y 6\%), y finalmente, con menos del $5 \%$ de las horas asalariadas trabajadas, quedan Actividades sanitarias, Servicios auxiliares, Transporte y almacenamiento, Actividades de los hogares, Consultarías y actividades técnicas y Actividades de servicios sociales.

Es en los sectores con una jornada laboral mayor donde implementar políticas conducentes a una reducción de jornada parece más factible, y donde tendría mayores efectos sobre la jornada media. Estos son los sectores en los que tradicionalmente se ha realizado mayor número de horas extras, entre otras cosas debido a que son sectores más atomizados para los trabajadores: trabajos del hogar, construcción, comercio, servicios auxiliares (trabajo externalizado) y hostelería y transporte. Entre todos ellos se realizaron el 36,13\% de todas las horas asalariadas trabajadas. 
Figura 40

Porcentaje de horas asalariadas trabajadas por sector (2012)

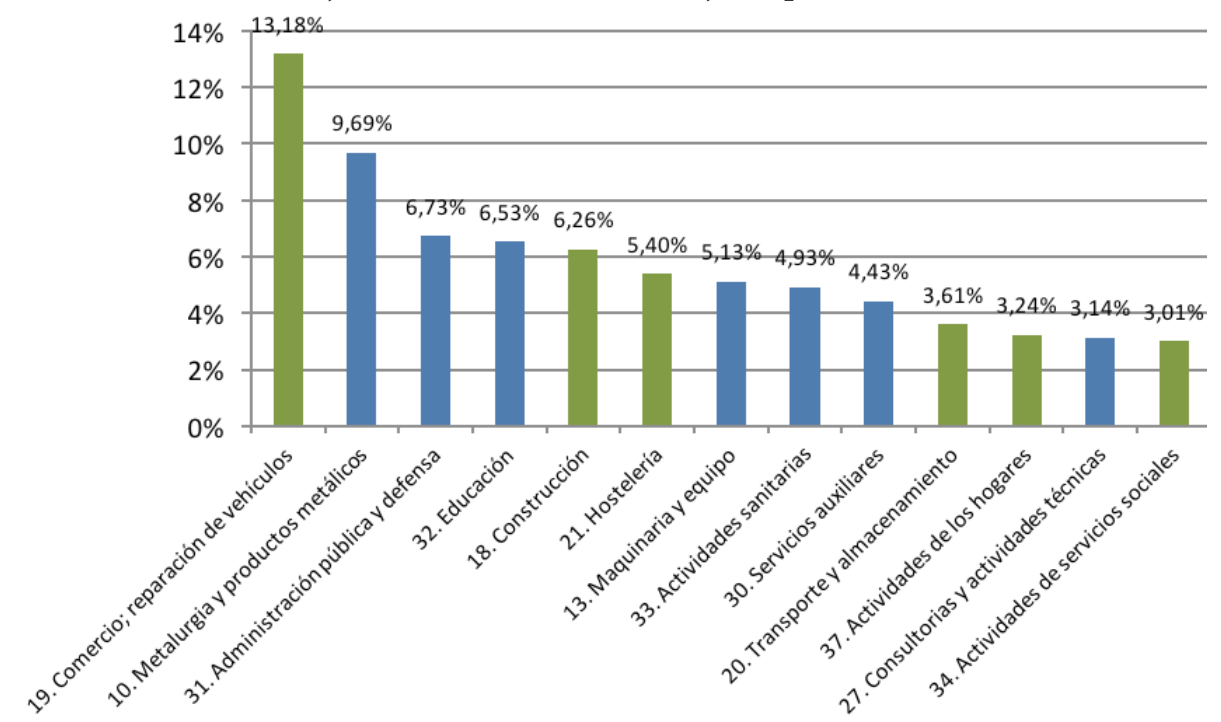

Nota: En verde figuran los sectores con jornadas anuales superiores a la media, y en azul los sectores con jornadas anuales inferiores a la media.

Fuente: elaboración propia, con datos de Eustat.

\subsection{Añadimos tres nuevos sectores}

En el apartado anterior se han tomado los sectores en los que e 2012 se trabajó más de un 3\% de las horas totales trabajadas en Gipuzkoa, con el fin de seleccionar los sectores en los que una política de reducción de jornada de trabaja tendría más impacto social. A la lista anterior hemos añadido tres sectores más, que no siendo los siguientes en la lista de sectores con más horas trabajadas, sí que consideramos que tienen unas características que les hacen ser relevantes a la hora de analizar las jornadas laborales anuales.

En primer lugar hemos añadido Material de transporte, con el 1,7\% de las horas trabajadas, debido a que tiene la jornada laboral anual más reducida después del sector Educación. Parece que es debido al convenio de la mayor empresa del sector (CAF), que podría servir como paradigma de reducción de tiempo de trabajo dentro de la situación actual.

Hemos ańadido también el sector de Actividades financieras y seguros, con el 2,26\% de las horas trabajadas, porque es un sector concentrado en un número reducido de empresas con altos beneficios en las que se podría intentar la aplicación de medidas de RTT. 
Finalmente hemos considerado el sector de Agricultura y Pesca, con solo un $0,69 \%$ de las horas realizadas, pero que es un sector en el que en los últimos años se ha aumentado el número de horas trabajadas, a pesar de la tendencia a la baja en el número de personas ocupadas ${ }^{10}$. Sector muy atomizado, con un gran número de puestos de trabajo a tiempo parcial, y con un peso relativamente grande de trabajadores autónomos frente a trabajadores asalariados.

Con estos tres sectores nuevos se llega a un $80 \%$ de las horas trabajadas.

\subsection{Jornada de las personas asalariadas en el sector}

En la Tabla 5 se recogen las jornadas anuales de los puestos de trabajo equivalentes a tiempo completo de los asalariados, y las jornadas anuales de las personas asalariadas.

Tabla 5

Jornada anual de los PTETC asalariados por sectores (2012)

\begin{tabular}{lrccc}
\hline \multicolumn{1}{c}{ Sector } & Horas (\%) & $\begin{array}{c}\text { Jornada anual } \\
\text { PTETC } \\
\text { asalariado }\end{array}$ & $\begin{array}{c}\text { Jornada } \\
\text { anual persona } \\
\text { asalariada }\end{array}$ & $\begin{array}{c}\text { Persona asal./ } \\
\text { PTETC asal. }\end{array}$ \\
\hline Comercio; reparación de vehículos & $13,18 \%$ & 1.704 & 1.648 & $96,72 \%$ \\
Metalurgia y productos metálicos & $9,69 \%$ & 1.654 & 1.616 & $97,66 \%$ \\
Administración pública y defensa & $6,73 \%$ & 1.627 & 1.611 & $99,03 \%$ \\
Educación & $6,53 \%$ & 1.429 & 1.347 & $94,21 \%$ \\
Construcción & $6,26 \%$ & 1.802 & 1.790 & $99,34 \%$ \\
Hostelería & $5,40 \%$ & 1.684 & 1.626 & $96,56 \%$ \\
Maquinaria y equipo & $5,13 \%$ & 1.656 & 1.636 & $98,79 \%$ \\
Actividades sanitarias & $4,93 \%$ & 1.602 & 1.574 & $98,24 \%$ \\
Servicios auxiliares & $4,43 \%$ & 1.689 & 1.560 & $92,37 \%$ \\
Transporte y almacenamiento & $3,61 \%$ & 1.684 & 1.660 & $98,56 \%$ \\
Actividades de los hogares & $3,24 \%$ & 1.827 & 1.033 & $56,52 \%$ \\
Consultorías y actividades técnicas & $3,14 \%$ & 1.666 & 1.612 & $96,78 \%$ \\
Actividades de servicios sociales & $3,01 \%$ & 1.639 & 1.600 & $97,61 \%$ \\
Actividades financieras y seguros & $2,26 \%$ & 1.710 & 1.685 & $98,52 \%$ \\
Material de transporte & $1,72 \%$ & 1.491 & 1.392 & $93,36 \%$ \\
Agricultura, ganadería y pesca & $0,69 \%$ & 1.892 & 1.433 & $75,72 \%$ \\
\hline Media Gipuzkoa & $100,00 \%$ & 1.667 & 1.581 & $94,83 \%$ \\
\hline
\end{tabular}

Fuente: elaboración propia, con datos de Eustat.

${ }^{10}$ Un registro de la evolución entre 1995 y 2012 de el número de personas ocupadas y asalariadas, así cómo toda una gama de indicadores para plantear la viabilidad sectorial de las políticas de reducción de tiempo de trabajo se recoge en Castrillón et al. (2016c). 
La última columna nos indica la proporción entre la jornada media anual de una persona asalariada en el sector y la jornada anual de puesto equivalente a tiempo completo (asalariado), en cada sector. Así tenemos como valores extremos que una persona empleada en Actividades de los hogares trabaja de media un 56\% de la jornada a tiempo completo (en Agricultura un 75\%), mientras que en Construcción y en Administración pública cada trabajador realiza un 99\% de la jornada anual a tiempo completo. Para el conjunto de Gipuzkoa, esta tasa alcanza casi un $95 \%$.

Estos índices son otra forma de representar la tasa de "parcialidad» de cada sector, de tal forma que en Actividades de los hogares la jornada media de un asalariado es algo más de la mitad de la jornada a tiempo completo, y en la Construcción, sin embargo, la jornada media de un asalariado es casi igual a la jornada correspondiente a tiempo completo.

\subsection{Comparación PTETC personas asalariadas/ocupadas}

Tabla 6

Jornada anual de los PTETC asalariados y empleados por sectores (2012)

\begin{tabular}{lrccc}
\hline \multicolumn{1}{c}{ Sector } & $\begin{array}{c}\text { Horas } \\
(\%)\end{array}$ & $\begin{array}{c}\text { Jornada anual } \\
\text { PTETC } \\
\text { asalariado }\end{array}$ & $\begin{array}{c}\text { Jornada anual } \\
\text { PTETC } \\
\text { ocupado }\end{array}$ & $\begin{array}{c}\text { Asalariado / } \\
\text { ocupado }\end{array}$ \\
\hline Comercio; reparación de vehículos & $13,18 \%$ & 1.704 & 1.785 & $95,45 \%$ \\
Metalurgia y productos metálicos & $9,69 \%$ & 1.654 & 1.682 & $98,38 \%$ \\
Administración pública y defensa & $6,73 \%$ & 1.627 & 1.600 & $101,63 \%$ \\
Educación & $6,53 \%$ & 1.429 & 1.552 & $92,10 \%$ \\
Construcción & $6,26 \%$ & 1.802 & 1.849 & $97,45 \%$ \\
Hostelería & $5,40 \%$ & 1.684 & 1.780 & $94,62 \%$ \\
Maquinaria y equipo & $5,13 \%$ & 1.656 & 1.696 & $97,65 \%$ \\
Actividades sanitarias & $4,93 \%$ & 1.602 & 1.630 & $98,27 \%$ \\
Servicios auxiliares & $4,43 \%$ & 1.689 & 1.767 & $95,62 \%$ \\
Transporte y almacenamiento & $3,61 \%$ & 1.684 & 1.734 & $97,11 \%$ \\
Actividades de los hogares & $3,24 \%$ & 1.827 & 1.800 & $101,49 \%$ \\
Consultorias y actividades técnicas & $3,14 \%$ & 1.666 & 1.768 & $94,23 \%$ \\
Actividades de servicios sociales & $3,01 \%$ & 1.639 & 1.682 & $97,47 \%$ \\
Actividades financieras y seguros & $2,26 \%$ & 1.710 & 1.702 & $100,51 \%$ \\
Material de transporte & $1,72 \%$ & 1.491 & 1.71 .6 & $86,86 \%$ \\
Agricultura, ganadería y pesca & $0,69 \%$ & 1.892 & 1.893 & $99,97 \%$ \\
\hline Media Gipuzkoa & & 1.667 & 1.718 & $97,05 \%$ \\
\hline
\end{tabular}

Fuente: elaboración propia, con datos de Eustat. 
En la Tabla 6 comparamos las jornadas medias anuales de los asalariados y del total de ocupados (incluyendo autónomos). Para ello hemos tomado la jornada anual de un puesto de trabajo ETC de un asalariado y lo hemos comparado con la jornada del correspondiente puesto de trabajo ETC de un ocupado. Las tasa menores (86, 92 y 94 en Material de transporte, Educación y Hostelería, respectivamente), indican que en estos sectores los asalariados trabajan menos que los autónomos, empleadores y demás estatus. Por el contrario, en Administración pública, Actividades de los hogares y Actividades financieras y seguros es en los sectores donde los asalariados trabajan algo más que los autónomos, probablemente porque casi todos los empleados son asalariados. La relación indica, que en general, los autónomos tienen jornadas laborales medias superiores a los asalariados.

\subsection{Jornada anual por persona ocupada, evolución por sectores}

Jornada anual por persona empleada $=$ horas totales $/$ personas ocupadas

La evolución por sectores entre los años 1995 y 2012 es la siguiente:

Figura 41

Jornada anual de las personas ocupadas, por sectores (2012)
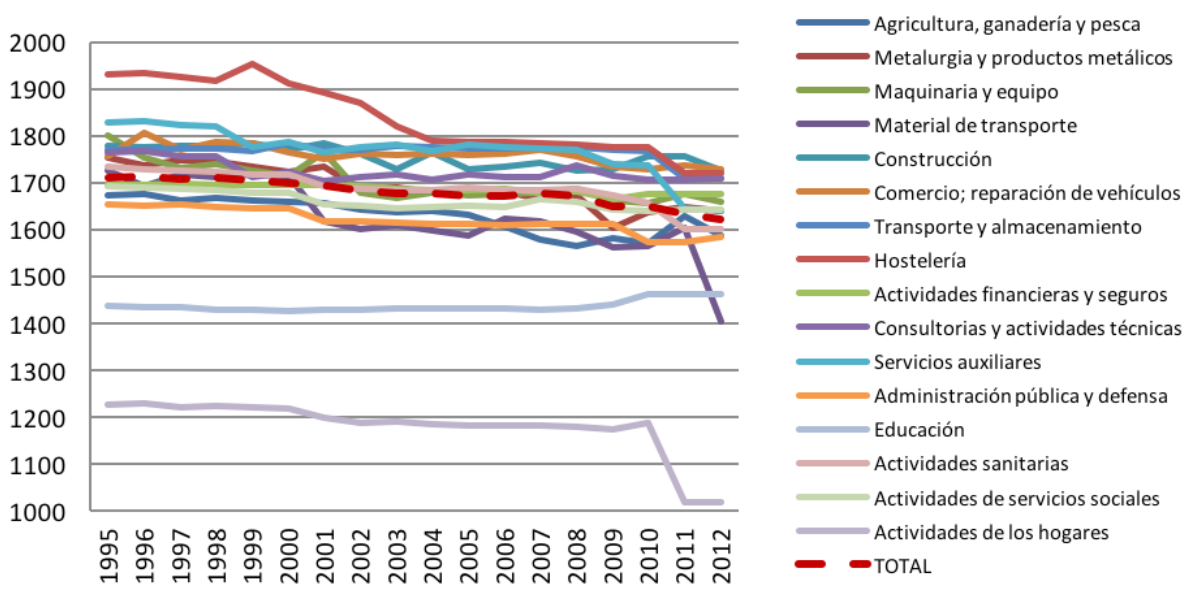

Fuente: elaboración propia, con datos de Eustat.

Los sectores más significativos por la reducción de la jornada anual media por persona son los siguientes: 
- Hostelería, que a pesar de ser en 2012 el sector con la segunda jornada laboral más larga, ha disminuido un $11 \%$ el número de horas trabajadas por persona desde 1995 .

- Material de transporte, con una disminución del 18,6\% de la jornada por persona, reducción especialmente acusada entre 2011 y 2012.

— Actividades de los hogares: debido a la regularización del año 2011, el número de personas registradas en este sector ha aumentado considerablemente, lo que ha hecho disminuir la jornada por persona en un $17 \%$.

Los sectores más significativos por el aumento de la jornada anual media por persona son los siguientes:

- Educación, que a pesar de tener la segunda jornada más corta por persona, ha aumentado dicha jornada en un $1,6 \%$.

Los otros sectores en los que ha aumentado la jornada laboral son Productos informáticos y electrónicos e Industria química, pero no aparecen entre los 16 sectores citados porque únicamente ocupan un $1,4 \%$ y $0,5 \%$ del total de horas trabajadas, respectivamente.

\subsection{Jornada anual por persona asalariada, evolución por sectores} das

Jornada anual por persona asalariada $=$ horas asalariadas $/$ personas asalaria-

Figura 42

Jornada anual de las personas asalariadas, por sectores (2012)
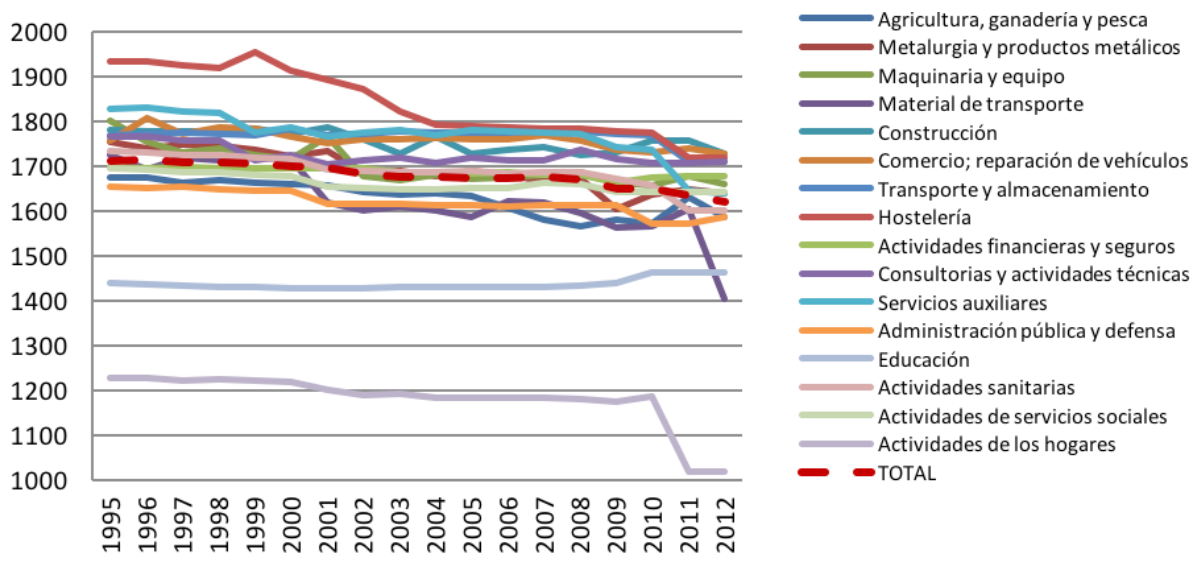

Fuente: elaboración propia, con datos de Eustat. 
Hemos visto anteriormente que teniendo en cuenta únicamente a las personas asalariadas (excluyendo autónomos), las jornadas anuales son más reducidas.

A destacar:

- El aumento de la jornada de los asalariados en Agricultura entre el año 2004 y 2005, debido a un incremento sustancial en el número de horas trabajadas (no hay cambio significativo en el número de personas asalariadas). Probablemente tenga que ver con cambios metodológicos a la hora de contabilizar el trabajo de los inmigrantes ${ }^{11}$.

- El aumento de la jornada de los asalariados de la Construcción, a partir del año 2008, aunque en los años anteriores había sufrido una lenta reducción, con lo que en el periodo 1995-2012 el incremento total ha sido del $2 \%$.

- Incremento de la jornada en Actividades financieras y seguros, a partir de 2009, aunque en el conjunto del periodo el aumento ha sido del $1 \%$.

- La disminución de la jornada anual por asalariado en el sector Actividades de los hogares, en el año 2012, debido a la regularización del sector, con lo que la reducción en el periodo 1995-2012 llega al $16 \%$.

— Disminución de la jornada anual de los asalariados en el sector de Material de transporte, tal y como se señala en el apartado anterior (presumiblemente en este sector las empresas son grandes, no hay autónomos, por lo que la jornada de los asalariados y del conjunto de personas empleadas es muy parecida: 1392 y 1404 horas, respectivamente).

— La jornada laboral media de las personas asalariadas se ha reducido desde 1.646 horas anuales en 1995, hasta 1.581 horas anuales en 2012, lo que supone una reducción de casi el $4 \%$, mayor que el resultado obtenido en el primer apartado, donde se veía que la reducción de la jornada de un PTETC asalariado se había reducido desde 1.721 horas anuales hasta 1.667 horas, una reducción del 3,12\%. Es decir, las personas asalariadas han reducido su jornada más que la reducción de los puestos de trabajo a tiempo completo, lo que indica una mayor proporción de personas trabajando a tiempo parcial.

11 El INE ha realizado una revisión de la metodología en 2005 para considerar el incremento de la población derivado del aumento de la inmigración, lo que se ha traducido en un aumento de la población activa, siendo el sector agrícola importante para le inmigración. Fuente: Ministerio de Agricultura (2007). 


\subsection{Jornada anual de autónomos y asalariados}

En la tabla siguiente se comparan las jornadas ${ }^{12}$ de los asalariados, con las jornadas de los no asalariados (autónomos y empleadores), para los sectores en que el número de autónomos es superior al $10 \%$. Hay que tener en cuenta que en algunos sectores no hay autónomos (Administración pública y Actividades de los hogares), y en otros el número de autónomos es poco relevante.

\section{Tabla 7}

Comparación de las jornadas anuales de asalariados y autónomos (2012)

\begin{tabular}{lcccc}
\hline & $\begin{array}{c}\text { Jornada } \\
\text { anual } \\
\text { autónomos }\end{array}$ & $\begin{array}{c}\text { Jornada } \\
\text { anual } \\
\text { asalariados }\end{array}$ & Asal./autón. & $\begin{array}{c}\% \text { autónomos } \\
\text { s. total } \\
\text { trabajadores }\end{array}$ \\
\hline Servicios auxiliares & 2.555 & 1685 & $65,96 \%$ & $9,36 \%$ \\
Hostelería & 2.138 & 1684 & $78,79 \%$ & $21,11 \%$ \\
Consultorías y actividades técnicas & 2.112 & 1666 & $78,87 \%$ & $22,85 \%$ \\
Comercio; reparación de vehículos & 2.121 & 1704 & $80,36 \%$ & $19,49 \%$ \\
Transporte y almacenamiento & 1.864 & 1684 & $90,33 \%$ & $27,84 \%$ \\
Construcción & 1.977 & 1802 & $91,13 \%$ & $26,87 \%$ \\
Agricultura, ganadería y pesca & 1.893 & 1892 & $99,95 \%$ & $68,71 \%$ \\
Media Gipuzkoa (todos los sectores) & 2.079 & 1667 & $80,20 \%$ & $12,33 \%$ \\
\hline
\end{tabular}

Fuente: elaboración propia, con datos de Eustat.

En general, los asalariados tiene jornadas inferiores a los no asalariados, dentro de una horquilla que va desde el $65 \%$ en el sector de Servicios auxiliares, hasta casi el $100 \%$ del sector agropecuario (en el que, por tanto, los asalariados tienen jornadas similares a los autónomos).

Para el conjunto de Gipuzkoa, y teniendo en cuenta los 38 sectores productivos, la jornada anual media de los asalariados (1.667 horas) supone el $80 \%$ de la jornada anual media de los autónomos (2.079 horas), con un 12\% de trabajadores autónomos sobre el total de trabajadores. Esto tiene un enorme contenido analítico a la hora de entender la composición orgánica del trabajo y del capital a nivel de cada sector, siendo la estructuración de la fuerza laboral más o menos asalariadas un componente central a la hora de plantear todo tipo de política de empleo.

Por remarcar algunos casos, cabe destacar el componente de auto-explotación que muestran las altas jornadas de los autónomos y empleadores en los servicios auxiliares, así como en menor medida en la hostelería, la consultoría y

12 Jornada media anual de un puesto de trabajo equivalente a tiempo completo, en ambos casos, para cada sector. 
el comercio. En estos tres últimos las personas asalariadas rondan el $80 \%$ de la fuerza laboral, siendo las diferentes formas de trabajo autónomo una de las cuestiones que escapa hoy a la comprensión de muchos analistas sociales y sindicales (Bifo, 2003). En mayor medida es el transporte y la construcción (27\%) y en la agricultura, ganadería y pesca (69\%) dónde esta parte de personas no asalariadas es mayor, siendo los efectos en términos de jornada menores ${ }^{13}$.

\section{Conclusiones}

Rasgos generales de la ocupación laboral y el empleo en Gipuzkoa:

En cuanto al número total de activos, parados y ocupados, y la distribución de estos por sectores, hay que destacar:

- El incremento paulatino del número de activos.

- Los altibajos de la tasa de paro, con unos valores máximos del 23\% a mediados de los años 90, una paulatina disminución hasta los mínimos del $5 \%$ en 2007, y un repunte desde el comienzo de la crisis hasta los valores actuales en torno al $13 \%$ en 2015.

- El aumento del número de ocupados en el sector servicios, duplicándose en el caso de Gipuzkoa.

- Un cierto declive en el número de ocupados en la industria, con el dato relevante de que en Gipuzkoa son casi la cuarta parte de los ocupados en el último año considerado, para un $14 \%$ en Espańa, y un $21 \%$ en la eurozona (pero en este último caso incluyendo la construcción).

- Un aumento de los ocupados en la construcción hasta el estallido de la burbuja inmobiliaria, y un retroceso posterior.

- Un lento declive en la agricultura, sector que ya era el que contaba con menos ocupados, con un cierto repunte en Gipuzkoa a partir del estallido de la crisis.

En cuanto a la edad de los trabajadores (y de la población en general), se observa un paulatino envejecimiento, en el que el número de jóvenes en edad de entrar al mercado laboral es únicamente el $65 \%$ de los trabajadores de más de 55 ańos y, por tanto, más cercanos a la jubilación. Destacar también que, en España, este índice de reemplazo poblacional es del 83\%, lo cuál parece una diferencia suficientemente significativa como para adquirir el rango de preocupante.

13 En la construcción y en la agricultura, ganadería y pesca las jornadas de autónomos son menores, sí, a la vez que también que menos observables en las estadísticas oficiales, dado el grado de informalidad y no contabilidad horaria —y, por tanto, auto-explotación potencial extrema—, que hay en ellos. 
Este envejecimiento, más agudo en Gipuzkoa, se reproduce también en lo que atañe a la población activa, viéndose en un ciclo corto desde el 2001 un notable descenso absoluto de la juventud de 20 a 29 años, sin duda de más largo recorrido en la mayoría de países de nuestro entorno.

En cuanto a los parados, es significativa la elevada tasa de paro (superior al $30 \%)$ de los más jóvenes por una parte, y el aumento de los desempleados de larga duración (más de dos años en paro) por otra, lo cual indica a su vez que el paro, antes más centrado en los jóvenes, se extiende a todos los grupos de edad. La tasa de paro de larga duración en Gipuzkoa ha pasado en un 0,4\% en 2007 a un $7,7 \%$ en 2014.

En cuanto a diferencias entre hombres y mujeres, es evidente la mayor precarización en el caso de las mujeres, que, a pesar de sufrir tasas de paro similares a las de los hombres desde el año 2007, ocupan con mucha mayor frecuencia que ellos puestos de trabajo a jornada parcial, temporales y con salarios un $25 \%$ inferiores a los de los hombres.

Desde el año 2007 la mayoría de los nuevos contratos han sido temporales (de duración definida), lo que ha hecho aumentar considerablemente el número puestos de trabajo de este tipo, que han llegado hasta un 23\% del total en 2014.

En relación al tipo de jornada, los trabajadores a tiempo parcial suponen una parte cada vez mayor de los ocupados, hasta llegar a ser uno de cada cinco ocupados en 2014.

Sobre los estatus ocupacionales hemos podido ver una parte importante de cooperativistas en Gipuzkoa, en mayor medida que en España, dada la larga tradición de esta modalidad de trabajo asociado en nuestro territorio. Por contra, la parte de las administraciones públicas en el empleo es menor. Es significativo el número de cooperativistas que hay en Gipuzkoa (un 3,8\% en 2014) comparado con el 2,6\% de la CAV o el 0,14\% del Estado.

La jornada media trabajada en Gipuzkoa ha disminuido a lo largo de los últimos años. Esto no quita para que la persistencia de un alto paro es, según Husson (2015), uno de los síntomas de una reducción no suficiente del tiempo de trabajo. Esta es la única vía factible de que el incremento constante de la productividad de las economías capitalistas se plasme en reducciones sustanciales y generalizadas de jornada, lo que permitiría el empleo de nuevos sectores de la población (De la Fuente y Zubiri, 2016a). En el caso de los asalariados, un puesto de trabajo equivalente a tiempo completo (PTETC) cubría en 1995 una jornada anual de 1.720 horas, y en 2012 esa jornada se había reducido hasta las 1.667 horas.

Por sectores, la distribución de jornadas es muy desigual, y teniendo en cuenta únicamente los sectores que ocupan más de un 3\% de las horas totales, las jornadas mayores de un PTETC se dan en actividades de los hogares (1.827, 
aunque hay que tener en cuenta que en este sector se da un índice de parcialidad muy alto) y Construcción (1.802), y las jornadas anuales más cortas se dan en Actividades Sanitarias (1.602) y Educación (1.429). Esto nos indica una vía de profundización en nuestro objeto de estudio que será abordada en detalle en Castrillón et al. (2016b; 2016c), antes de pasar a una proyecciones para explorar la viabilidad de las políticas de reducción del tiempo de trabajo en, por ejemplo, Gipuzkoa (Castrillón et al., 2016d).

\section{Bibliografía}

Albarracín Sánchez, Daniel (2003): De la utopía postindustrial a la crisis de las sociedades salariales de servicios: En torno al ciclo del capital y la identidad de clase de los trabajadores españoles en el capitalismo tardio, Tesis Doctoral dirigida por Luis Enrique Alonso Benito, Madrid, UCM, 638 p.

Álvarez Peralta, Nacho, Luengo, Fernando y Uxó, Jorge (2013): Fracturas y crisis en Europa, Madrid, Ed. Clave Intelectual, 342 p.

Aragón, Jorge, Cruces, Jesús, Martínez, Alicia y Rocha, Fernando (2012): El tiempo de trabajo y la jornada laboral en España, Madrid, Comisiones Obreras, 248 p.

Azkarraga Etxagibel (2006): Identitate kooperatiboaren bilakaera: Arrasateko kooperatiba esperientzia, Soziologian Doktore Tesia, Zuzendaria: Imanol Zubero Beaskoetxea, Euskal Herriko Unibertsitatea, 1357 p.

Aznar, Guy (1994): Trabajar menos para trabajar todos, Madrid, HOAC.

BIfo, Franco Berardi (2003): La fábrica de la infelicidad. Nuevas formas de trabajo y movimiento global, Madrid, Traficantes de Sueños, $191 \mathrm{p}$.

Castrillón Serna, Verónica, Zendoia Sainz, Jose Mari y Zubiri Rey, Jon Bernat (2016b): «Distribución funcional de la renta y costes laborales en Gipuzkoa: un estudio empírico para la reducción del tiempo de trabajo», Lan Harremanak. Revista de Relaciones Laborales, n. ${ }^{\circ}$ 34, 2016 (1).

- (2016c): «Indicadores socio-laborales de viabilidad por sectores de una reducción del tiempo de trabajo en Gipuzkoa», Lan Harremanak. Revista de Relaciones Laborales, n. ${ }^{\circ} 34,2016(1)$.

- (2016d): «Propuestas de reducción del tiempo de trabajo en Gipuzkoa», Lan Harremanak. Revista de Relaciones Laborales, n. ${ }^{\circ}$ 34, 2016 (1).

De la Fuente Lavín, Mikel y Zubiri Rey, Jon Bernat (2016a): «Significado histórico y actualidad de las políticas de reducción del tiempo de trabajo», Lan Harremanak. Revista de Relaciones Laborales, n. ${ }^{\circ}$ 34, 2016 (1).

ELA-Gabinete de Estudios (2014): «Informe sobre salarios y empleo en Euskal Herria», Manu Robles Arangiz, 17 p.

Errasti Amozarrain, Anjel Mari (2003): Kooperatiben garapena globalizazioaren garaian: Nazioarteko hedapenaren politika sozioekonomikorako gakoak, Enpresa ta Ekonomia Zientzian Doktore Tesia, Zuzendaria: Pilar Elgoibar Larrańaga, Euskal Herriko Unibertsitatea, $467 \mathrm{p}$.

Gaindegia (2014): Lan merkatuaren egoera Euskal Herrian / Situación del mercado laboral en Euskal Herrian, Andoain, Euskal Herriko ekonomia eta gizarte garapenerako behategia, 87 p. 
ImAz, Jose Inazio (2006a): Lanaldi murrizketari buruzko eztabaida, 1995-2005, Donostia, Utriusque Vasconiae, 284 p.

- (2006b): "La reducción del tiempo de trabajo, 1995-2005», Soziologiazko Euskal Koadernoak-Cuadernos Sociológicos Vascos, n. 21.

- (2003): Lanaldi murrizketa eta banaketari buruzko eztabaida Euskadin, Tesia EHUn, Zuzendaria: Imanol Zubero Beaskoetxea, 527 p.

Larrañaga Sarriegui, Mercedes (2005): "Mujeres y mercado de trabajo en la CAPV», Lan Harremanak. Revista de Relaciones Laborales, n. ${ }^{\circ} 13,13-34$.

Mendizabal Etxabe, Antxon, Bakaikoa Azurmendi, Baleren, Errasti Amozarrain, Anjel Mari (1995): Aproximación a la economía social en Euskal Herria. Presente y retos de futuro, Ekonomiaz: Revista vasca de economía, N. ${ }^{\circ} .33,1995$ (Ejemplar dedicado a: Economía de la participación), pp. 154-183.

Miguélez, Fausto y Prieto, Carlos (1999) (dir. y coord.): Las Relaciones de Empleo en España, Madrid, Siglo XXI.

Ministerio de Agricultura, Pesca y Alimentación (2007): «El empleo agroalimentario y pesquero en Espańa", Hoja de Información Agro-Económica, n. ${ }^{\circ}$ 8, marzo, 2 p.

Rodríguez Âlvarez, Arantxa y Larrañaga Sarriegui, Mercedes (1999): «El tiempo de trabajo y su distribución por sexos en la Comunidad Autónoma Vasca», Lan Harremanak: Revista de Relaciones Laborales, n. ${ }^{\circ}$ 1, Ejemplar dedicado a: El tiempo de trabajo, 193-219.

Zamagni, Vera (2001): Historia económica de la Europa contemporánea. Barcelona, Crítica.

Zubiri Rey y Jon Bernat (2014): «El empleo juvenil como vector de transformación de las sociedades salariales de servicios», Boletín ECOS del Cip-Ecosocial, n. ${ }^{\circ} 27$, junio 2014, 15 p. 